\section{D) Check for updates}

Cite this: Inorg. Chem. Front., 2019 6, 3398

Received 15th July 2019, Accepted 26th August 2019

DOI: 10.1039/c9qi00875f

rsc.li/frontiers-inorganic

\title{
Electro-activity and magnetic switching in lanthanide-based single-molecule magnets
}

\begin{abstract}
Olivier Cador, (ID) Boris Le Guennic (iD) and Fabrice Pointillart (iD *
The control of the single-molecule magnet (SMM) behaviour is highly challenging but crucial to design molecular materials suitable for potential applications in molecular devices. To switch the SMM behaviour, a plethora of external stimuli can be employed such as electro-activity, solvents, protonation, magnetic and electric fields, and light. All these stimuli induce structural modifications and thus, to some degree, changes in the electronic properties. Lanthanide ions are elements extremely sensitive to crystal field effects i.e. they are sensitive to any structural changes making them ideal candidates for the design of molecular switches. This article reviews both the pool of electro-active lanthanide SMMs and the various switching modes such as redox-, solvato-, photo- and proton-switching lanthanide SMM behaviours. These examples highlight the importance of inducing electronic distribution changes close to the lanthanide centre to reach a complete ON-OFF switching but also the preponderance of further structural changes and intermolecular interactions to modulate the magnetic properties. The present review should convince scientific communities that the use of lanthanide ions in the design of molecular switches is a promising strategy.
\end{abstract}

\section{Introduction}

Next generation devices such as hard disks would use molecular-scale components instead of the actual silicon-based electronics. Molecules able to retain their magnetization in a given direction were discovered in the early 90s with the famous $\mathrm{Mn}_{12}$ cluster. ${ }^{1}$ Such molecules behave as a tiny magnet

F-35000 Rennes, France.E-mail: fabrice.pointillart@univ-rennes1.fr

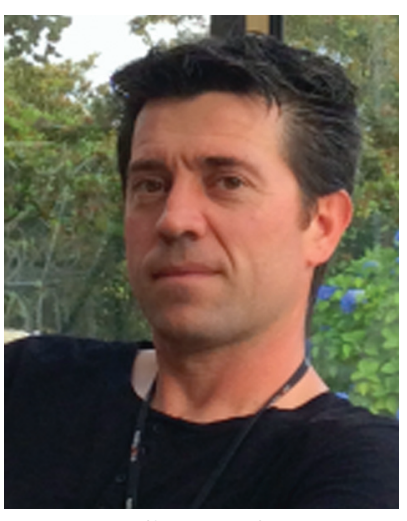

Oliver Cador
The research activities of Olivier Cador started in 1994 in Bordeaux (France). He mainly focused on the studies of the magnetic properties of systems with various dimensionalities, from nanoparticles to isolated molecules which show quantum behaviours, and finally to magnets with atypical behaviours. In Rennes, his aim was at first to develop the synergy between electronic properties, such as magnetism and electrical conductivity, in new molecular edifices based on organic/inorganic networks. He orients now his research field to Single Molecule Magnets (SMMs) based on lanthanides.

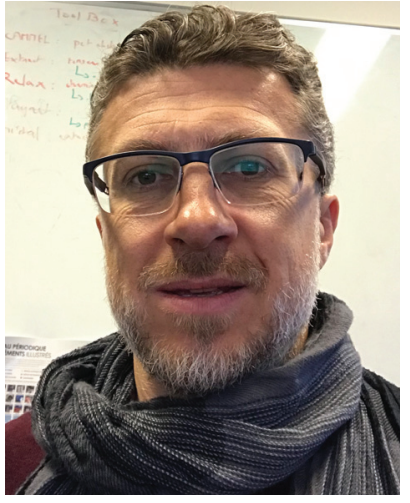

Boris Le Guennic
Boris Le Guennic received his Ph.D. in Chemistry from the University of Rennes in 2002. He then successively moved to the Universities of Erlangen, Buffalo, and Bonn for postdoctoral stays in the groups of Jochen Autschbach and Markus Reiher. In 2005, he was appointed as a CNRS researcher at ENS de Lyon (France). In 2011, he moved to the Chemical Sciences Institute of Rennes (University of Rennes, France) where he is currently a Senior CNRS researcher. His research is devoted mainly to the application of quantum chemical methodologies for the interpretation of magnetic and optical properties in transition metal and f-element complexes, with particular emphasis on lanthanidebased single molecule magnets. 
at the molecular scale and are called single-molecule magnets (SMMs). While such objects were built from transition metals until the beginning of the 2000s, lanthanide ions became rapidly good candidates for the design of SMMs due to their high magnetic moment and strong magnetic anisotropy. ${ }^{2}$ Recently two crucial factors have been dramatically improved that allow lanthanide-based SMMs to be back in the race for potential applications in high-density data storage, ${ }^{3}$ and also in quantum computing ${ }^{4}$ and spintronics: ${ }^{5}$ the high blocking temperature $^{6}$ and the level of understanding of the magnetic properties. Indeed the dynamics of a SMM can be modelled by the quantitative formulation of the relaxation time $\tau:^{7}$

$$
\tau^{-1}=\underbrace{A H^{m} T}_{\text {Direct }}+\underbrace{C T^{n}}_{\text {Raman }}+\underbrace{\tau_{0}^{-1} \exp \left(-\frac{\Delta}{T}\right)}_{\text {Orbach }}+\tau_{\mathrm{QTM}}^{-1}
$$

This relaxation time is composed of thermally-dependent (first three terms in eqn (1)) and thermally-independent (last term in eqn (1)) regimes. The thermally assisted processes between two states $|b\rangle$ and $|a\rangle$ are illustrated in Scheme 1.

(i) The direct process involves a single phonon and needs the application of an external magnetic field. This process is slightly thermal dependent but strongly field dependent and characterized by the parameter $A$ and the exponent $m$ (eqn (1)) where $m$ is fixed to 2 for non-Kramers ions and 4 for Kramers ions. (ii) The Raman process involves a virtual state and the simultaneous absorption/emission of two phonons. It is thermally-dependent and characterized by the parameter $C$ and the exponent $n$ (eqn (1)) which usually takes the value of 7 for non-Kramers ions and 9 for Kramers ions but could be lowered when both acoustic and optical phonons are involved in the relaxation process. ${ }^{8}$ (iii) The Orbach process involves real states and the simultaneous absorption/emission of two phonons. It gives the energy barrier $(\Delta)$ and has to be favoured to obtain high-performance SMMs. (iv) The QTM (not illus-

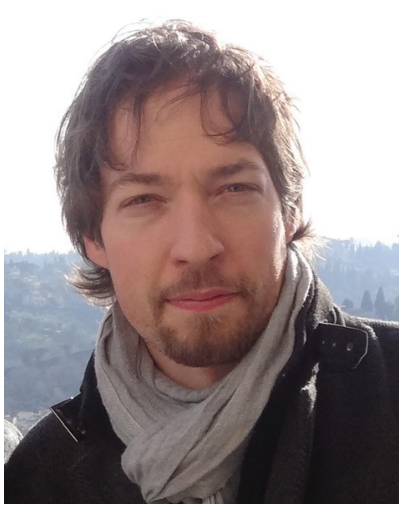

Fabrice Pointillart
Fabrice Pointillart received his PhD from the Pierre et Marie University in 2005, supervised by Profs. Cyrille Train and Michel Verdaguer. After a two-year period of postdoctoral research at the University of Florence with Prof. Roberta Sessoli, he joined the University of Rennes 1 in 2007 as a CNRS researcher. His current research interests are focused on single-molecule magnets of lanthanides associated with other properties such as chirality, luminescence and spin-crossover. He was awarded the CNRS bronze medal in 2014 and the junior prize of the Coordination Chemistry Division of the French Chemical Society in 2017 and received the ERC Consolidator Grant in 2016.

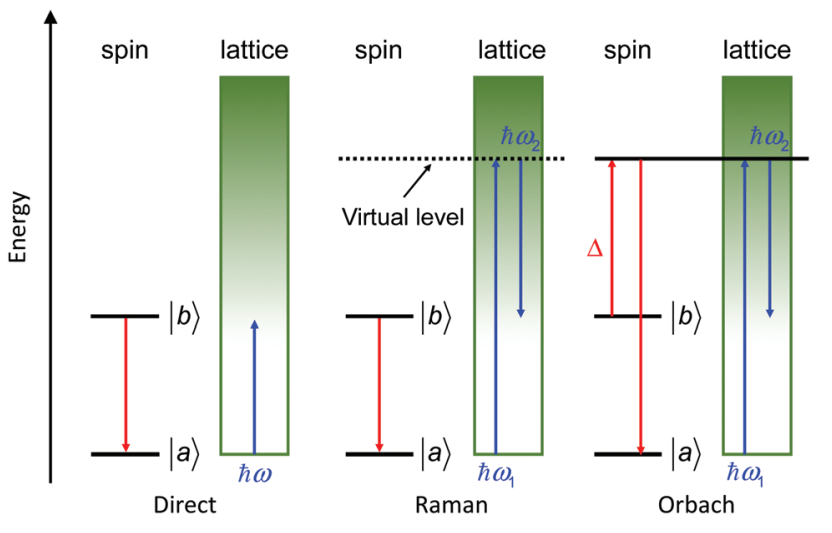

Scheme 1 Illustration of the three thermally assisted relaxation processes between two states $|b\rangle$ and $|a\rangle$.

trated in Scheme 1) induces transitions between doublet states due to the distortion from the perfect axial symmetry ${ }^{9}$ and dipolar ${ }^{10}$ or hyperfine ${ }^{11}$ interactions.

Even more challenging is the design of molecular materials whose physical properties can be controlled by external stimuli such as temperature, pressure, light irradiation, and magnetic field (Scheme 2). ${ }^{12}$ In fact the future circuits and devices composed of molecular-scale components should be able to switch between distinct states at high speeds with the input of minimal energy. ${ }^{13}$ To date, most of the transition metal-based magnetic switches in which the SMM behavior is modulated under an external stimuli were obtained when the electronic properties are strongly affected. Thus photo-irradiation induced change of the spin state,${ }^{14}$ while oxidizing or reducing agents induced change of the oxidation state of the organic ligand ${ }^{15}$ or the metal centre. ${ }^{16}$ Only recently, a few examples of solvato-switching of the SMM behavior were reported for transition metals. ${ }^{17}$

Concerning lanthanide complexes, several examples of magnetic switching have appeared in the literature these last five years. This review aims to summarize these recent examples. The next section is devoted to the quite large pool of redox-active lanthanide SMMs while the third section shows how the redox activity of the ligand or the metal can be used to modulate the SMM behavior. The next two sections are

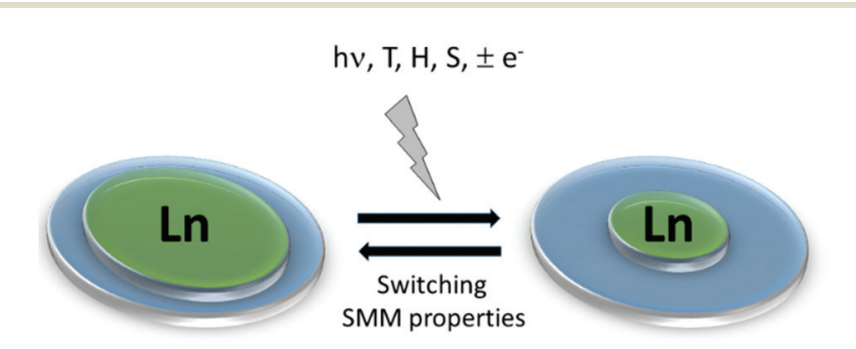

Scheme 2 Lanthanide-based systems displaying switching of their SMM behavior under various stimuli such as light irradiation $(h \nu)$, temperature $(T)$, magnetic field $(H)$, solvent $(S)$ and oxidizing/reducing agent $\left( \pm e^{-}\right)$. 
focused on the solvato- and photo-switching SMMs. Finally the sixth section is devoted to proton-switching SMMs. Through reading this review, the goal is to detail the different possibilities of inducing magnetic modulations giving some clue about the degree as well as the origin of the observed magnetic modulations.

\section{Electro-active single-molecule magnets}

In this review the notion of electro-activity is attributed to species which can be easily oxidized or reduced i.e. with potentials (electro)chemically accessible $|E|<2.5 \mathrm{~V}$ vs. SCE. It is worth noting that the redox activity is exclusively centred on the organic ligands. Thus the most known electro-active ligands, i.e. tetraoxolene, phthalocyanine and tetrathiafulvalene, involved in the design of electro-active SMMs are described.

\subsection{Tetraoxolene based single-molecule magnets}

The tetraoxolene-based ligands have a high potential interest level because they could be obtained in their closed shell dianionic and radical trianionic forms (Fig. 1a) giving potential access to radical bridging lanthanide species with possible interesting magnetic properties. ${ }^{18}$ Nevertheless among the several tetraoxolene-bridged dinuclear complexes of lanthanides which are reported in the literature, their magnetic properties are not studied. ${ }^{19}$

(a)<smiles>[R]C1=C([O-])C(=O)C(OC(C)C)C([R])C1=O</smiles><smiles>[R]C1C(=O)C(=O)C(O)C([R])C1=O</smiles><smiles>[R]c1c([O-])c([2H])c(O)c([O-])c1[O-]</smiles>

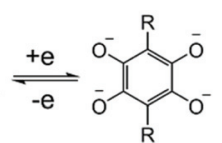

(b)
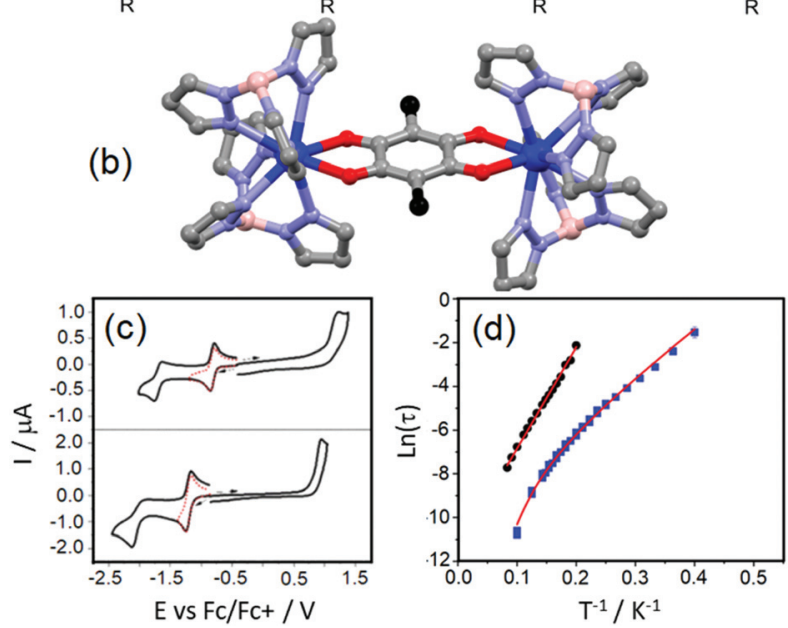

Fig. 1 (a) Electrochemical processes for tetraoxolene ligands. (b) Molecular structures of the dinuclear complexes 1 ( $\mathrm{R}=\mathrm{Cl}$ in black) and 2 ( $\mathrm{R}=\mathrm{CH}_{3}$ in black). (c) Cyclic voltammograms of the yttrium analogues of 1 (up) and 2 (below). (d) Arrhenius plot of relaxation rates of 1 (blue squares) and 2 (black spots) in a 1600 Oe applied magnetic field with the best fits (red lines, see main text for descriptions). Colour code: carbon: grey, nitrogen: light blue, boron: pink, oxygen: red and dysprosium: blue. Adapted from ref. 20.
The unprecedented deep magnetic study of a dinuclear complex involving lanthanide ions and tetraoxolene ligands was reported by C. Boskovic and collaborators in $2017 .^{20}$ The Dy(III) derivatives were obtained by the one-pot reaction of hydrotris(pyrazolyl)borate $\left(\mathrm{HB}(\mathrm{pz})_{3}{ }^{-}\right)$, the corresponding dysprosium salt and doubly deprotonated chloranilate $\left(\mathrm{ca}^{2-}\right)$ ligands. The X-ray structures revealed the formation of dinuclear complexes in which the $\mathrm{ca}^{2-}$ ligands $\left(\mathrm{R}=\mathrm{Cl}\left(\mathbf{L}^{\mathbf{1}}\right)\right.$ and $\mathrm{R}=$ $\mathrm{CH}_{3}\left(\mathbf{L}^{2}\right)$ ) bridged two lanthanide ions and the $\mathrm{HB}(\mathrm{pz})_{3}{ }^{-}$ anions played the role of blocking ligands (Fig. 1b). The nature of the substituents on the $\mathrm{ca}^{2-}$ bridges induced both the electronic effect and change from dodecahedral for $\left[\left(\left(\mathrm{HB}(\mathrm{pz})_{3}\right)_{2} \mathrm{Dy}\right)_{2}\left(\mu-\mathbf{L}^{\mathbf{1}}\right)\right]$ (1) to square antiprismatic for $\left[\left(\left(\mathrm{HB}(\mathrm{pz})_{3}\right)_{2} \mathrm{Dy}\right)_{2}\left(\mu-\mathbf{L}^{2}\right)\right]$ (2) coordination environments which induced changes in the electrochemical and magnetic properties. The compounds with both $\mathbf{L}^{\mathbf{1}}$ and $\mathbf{L}^{\mathbf{2}}$ ligands displayed two quasi-reversible reduction processes $(-0.96$ to $-0.81 \mathrm{~V}$ and -1.73 to $-1.65 \mathrm{~V}$ vs. $\mathrm{Fc} / \mathrm{Fc}^{+}$) corresponding to the formation of the radical tri-anionic and tetra-anionic species, and one irreversible oxidation process ( 0.89 to $1.18 \mathrm{~V} v s$. $\left.\mathrm{Fc} / \mathrm{Fc}^{+}\right)$corresponding to the formation of the radical mono-anionic species (Fig. 1c). All the redox processes have been attributed to tetraoxolene-based ligands. ${ }^{21}$ The substitution of the chloride with methyl groups induced a negative shift of the reduction processes of $0.2-0.3 \mathrm{~V}$ because of the electron donating character of the methyl group making the oxidation of $\mathbf{L}^{2}$ more difficult compared to $\mathbf{L}^{\mathbf{1}}$. The dynamic magnetic properties of $\mathbf{1}$ and $\mathbf{2}$ revealed a frequency dependence of the magnetic susceptibility at high frequency.

Once the QTM is suppressed by an optimal field (1600 Oe), the magnetic relaxation of 2 occurred through the sole Orbach regime $\left(\Delta=47 \mathrm{~K}\right.$ and $\left.\tau_{0}=1.0 \times 10^{-5} \mathrm{~s}\right)$ while 1 displayed magnetic relaxation through both Orbach $\left(\Delta=24 \mathrm{~K}\right.$ and $\tau_{0}=$ $\left.1.0 \times 10^{-5} \mathrm{~s}\right)$ and Raman $\left(C=2.7 \times 10^{-3} \mathrm{~S} \mathrm{~K}^{-n}\right.$ with $n$ fixed to 7$)$ regimes (eqn (1), Fig. 1d). The electrochemistry attested the possibility of isolating the radical tri-anionic oxidation state of the bridges as shown and discussed in section 3.1.

\subsection{Phthalocyanine based single-molecule magnets}

Phthalocyanine (Pc) ligands are well-known in molecular magnetism because the first lanthanide-based SMM discovered in 2003 was the $\mathrm{Tb}(\mathrm{Pc})_{2}$ double decker sample. ${ }^{22}$ These kinds of double decker compounds present a high anisotropy barrier ${ }^{23}$ making them potential candidates for applications in high density storage and spintronic devices. Heteroleptic lanthanide porphyrin (Por)-bisphthalocyanine $\left(\mathbf{L}^{3}\right)$ triple decker complexes $\left(\mathbf{L}^{3}\right) \operatorname{Ln}\left(\mathbf{L}^{3}\right) \operatorname{Ln}($ Por $)(\operatorname{Ln}=\mathrm{Tb}(\mathrm{III})$ (3) and Dy(III) (4)) were synthesized via microwave-assisted preparation. ${ }^{24}$ A complete electrochemical study showed that such complexes highlighted four one-electron oxidations and three one-electron reductions which are centred on the ligands. The oxidation and reduction potentials of the $\mathbf{L}^{3}$ ligand were identified at 0.50 and $-0.65 /-1.10 \mathrm{~V}$ vs. $\mathrm{Fc} / \mathrm{Fc}^{+}$, respectively. The direct current (dc) magnetic properties of 3 and 4 showed ferromagnetic dipolar interactions at low temperature. 
The alternating current (ac) magnetic properties under an applied magnetic field of 1000 Oe (in order to suppress the QTM contribution from eqn (1)) demonstrated the SMM behaviour for 3 with two main magnetic relaxations i.e. an Orbach thermally dependent regime at high temperature $(\Delta=$ $132.0 \mathrm{~K}$ and $\tau_{0}=5.0 \times 10^{-9} \mathrm{~s}$ ) and an under barrier direct mechanism at low temperature $\left(A=1.65 \times 10^{5} \mathrm{~s}^{-1} \mathrm{~K}^{-1} \mathrm{~T}^{-m}\right.$ with $m$ fixed to 4 ).

However the advantages of the Pc ligands having accessible redox potentials ${ }^{25}$ can be problematic when attempting to deposit them on the $\mathrm{Cu}(111)$ surface $^{26}$ because unexpected reduction can occur the same as for $\mathrm{Mn}_{12}$ complexes on the $\mathrm{Au}(111)$ surface. $^{27}$ Thus Veciana's group designed new Pc derivatives in which the Pc is functionalized by phthalimides for stabilising the anionic double-decker complexes TBA $\left[\mathrm{Tb}\left(\mathbf{L}^{n}\right)_{2}\right](5)-(7)$ (TBA is tetrabutylammonium). ${ }^{28}$ The success of the synthetic strategy was highlighted with electrochemical characterisation which presents strong shifts of $0.6-0.8 \mathrm{~V}$ depending on the nature of the phthalimide decorated group $\left(\mathrm{R}=-\mathrm{C}_{15} \mathrm{H}_{31}\left(\mathbf{L}^{\mathbf{4}}\right)(\mathbf{5}),-\mathrm{C}_{3} \mathrm{H}_{7}\left(\mathbf{L}^{\mathbf{5}}\right)(\mathbf{6})\right.$ and $\left.-\mathrm{CH}\left(\mathrm{CH}_{3}\right) \mathrm{Ph}\left(\mathbf{L}^{\mathbf{6}}\right)(7)\right)$ (Fig. 2). The two oxidation potentials and the two reduction potentials are found at $+0.3 /+0.8 \mathrm{~V}$ and $-0.9 /-1.2 \mathrm{~V} v s$. $\mathrm{Fc} / \mathrm{Fc}^{+}$ compared to $0.0 /-0.4 \mathrm{~V}$ and $-1.6 /-1.8 \mathrm{~V} v s$. $\mathrm{Fc} / \mathrm{Fc}^{+}$for the unsubstituted Pc ligand in $\mathrm{TBA}\left[\mathrm{Tb}(\mathrm{Pc})_{2}\right]^{29}$

The ac magnetic measurements showed classical SMM behaviour with both the thermally activated Orbach relaxation process and QTM at lower temperature. ${ }^{30}$ The fit of the Orbach regime led to energy barrier values with pre-exponential factors of $640 \mathrm{~K}$ and $\tau_{0}=6.35 \times 10^{-11} \mathrm{~s}$ for $5,616 \mathrm{~K}$ and $\tau_{0}=$

(a)
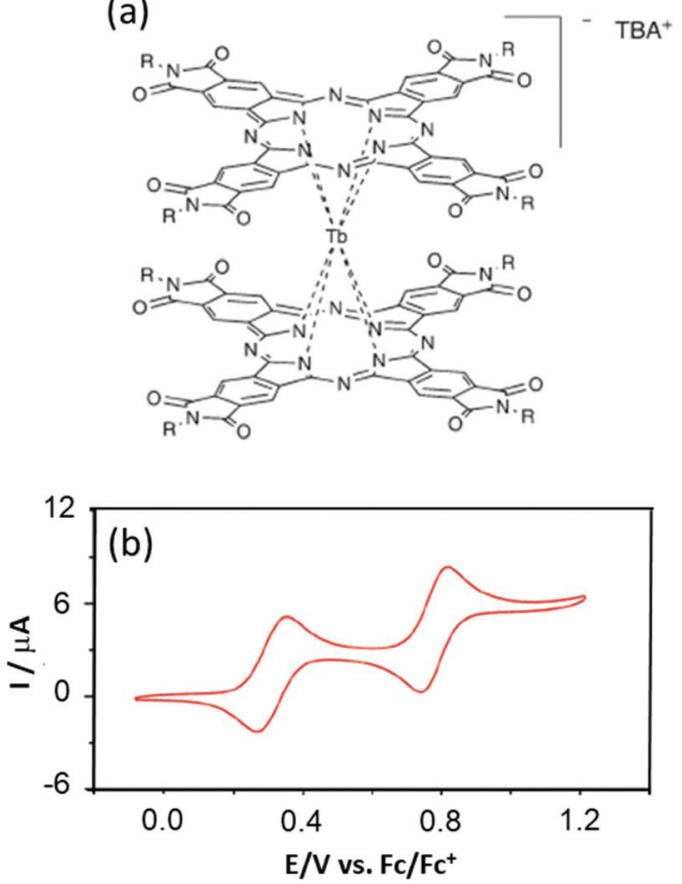

Fig. 2 (a) Molecular structures of the $\operatorname{TBA}\left[\mathrm{Tb}\left(\mathrm{L}^{n}\right)_{2}\right]$ complexes $(\mathrm{R}=$ $-\mathrm{C}_{15} \mathrm{H}_{31}\left(\mathrm{~L}^{4}\right)(5),-\mathrm{C}_{3} \mathrm{H}_{7}\left(\mathrm{~L}^{5}\right)(6)$ and $-\mathrm{CH}\left(\mathrm{CH}_{3}\right) \mathrm{Ph}\left(\mathrm{L}^{6}\right)$ (7)). (b) Cyclic voltammograms of 7 . Adapted from ref. 28.
$1.34 \times 10^{-10} \mathrm{~s}$ for 6 , and $666 \mathrm{~K}$ and $\tau_{0}=2.22 \times 10^{-11} \mathrm{~s}$ for 7 . For the three derivatives a butterfly-shape hysteresis is observed at $2 \mathrm{~K}$ in accordance with the combination of Orbach and QTM magnetic relaxation processes. ${ }^{31}$ The strong shift in redox potentials has no effect on the magnetic properties and the nature of the substituent only slightly acted on the QTM regime.

\subsection{Tetrathiafulvalene based single-molecule magnets}

The tetrathiafulvalene (TTF) derivatives are probably one of the most expanded and used redox-active classes of compounds. They have been intensively employed to design molecular conductors and superconductors. ${ }^{32}$ One of their advantages is the fact that they can be easily decorated with one to four coordinated groups ${ }^{33}$ to design $d-\pi$ or $f-\pi$ systems. Such a synthetic strategy allowed the combination of both electro-activity and magnetic/luminescence properties. ${ }^{34}$

J.-L. Zuo's group is very active in the field of electroactive lanthanide SMM. In 2013, they exploited the ability of a $\pi$-conjugated TTF-Schiff base ligand $\left(\mathbf{L}^{7}=2,2^{\prime}-((2-(4,5-\right.$ bis(methylthio)-1,3-dithiol-2-ylidene)-1,3-benzodithiole-5,6-diyl) bis-(nitrilomethylidyne)bis(4-chlorophenolate) $)^{35}$ to coordinate lanthanides $^{36}$ for obtaining a redox-active field-induced SMM. $^{37}$ The X-ray structure showed that the system $\left[\left(\mathbf{L}^{7}\right)\right.$ Dy $\left.\left(\mathrm{L}_{\mathrm{OEt}}\right)\right]$ (8) could be described as a mononuclear complex in which the Dy(III) ion is coordinated in the $\mathrm{N}_{2} \mathrm{O}_{2}$ pocket of the TTF-fused Schiff base ligand and capped by the tripodal metallo complex $\mathrm{L}_{\mathrm{OEt}}{ }^{-}$(where $\mathrm{L}_{\mathrm{OEt}}{ }^{-}=\left[\left(\eta^{5}-\mathrm{C}_{5} \mathrm{H}_{5}\right) \mathrm{Co}(\mathrm{P}(=\mathrm{O})\right.$ $\left.\left.(\mathrm{OEt})_{2}\right)_{3}\right]^{-}$) resulting in a $\mathrm{N}_{2} \mathrm{O}_{5}$ seven-coordinated Dy(III) centre (Fig. 3).

The electrochemical properties of $\mathbf{8}$ exhibited two reversible single-electron oxidation waves localized at $0.87 \mathrm{~V}$ and $1.19 \mathrm{~V}$ vs. SCE corresponding respectively to the formation of the radical cationic and dicationic species as shown in Fig. 4a for the TTF core. These potentials are slightly cathodically shifted compared to the free ligand $\mathbf{L}^{7}(0.91 \mathrm{~V}$ and $1.25 \mathrm{~V})$ which is the opposite trend to that expected through coordination. The authors attributed this negative shift to the competitive

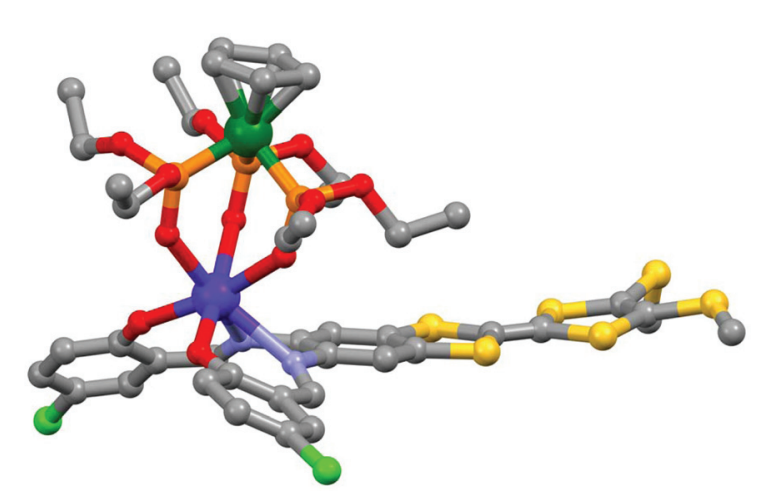

Fig. 3 Molecular structure of $\mathbf{8}$. Hydrogen atoms and solvent of crystallization are omitted for clarity. Colour code: carbon: grey, nitrogen: light blue, phosphorus: orange, oxygen: red, sulphur: yellow, chloride: green, cobalt: dark green and dysprosium: blue. Adapted from ref. 37 . 
(a)

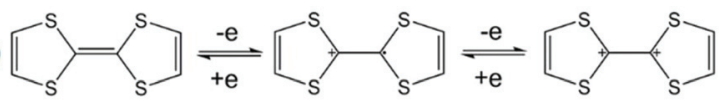

(c)

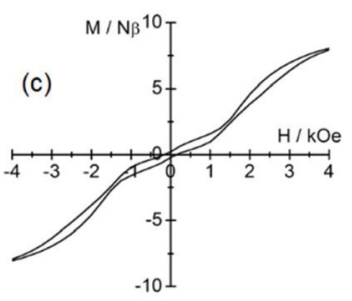

Fig. 4 (a) Electrochemical processes for the TTF fragment. (b) Molecular structure of 9. (c) Hysteresis loop of 9 at $0.5 \mathrm{~K}$. Colour code: fluoride: light green and sulphur: yellow. Adapted from ref. 37 and 38 .

deprotonation effect (from phenol to phenolate) associated with the lanthanide coordination. The magnetization dynamic of 8 was investigated by alternating current magnetic measurements. Due to the efficient QTM, no maxima of the out-ofphase component of the magnetic susceptibility were observed and an optimal field of 4000 Oe was applied leading to thermally activated magnetic relaxation processes.

The corresponding curve obtained by the Arrhenius law was fitted with an energy barrier of $\Delta=41.6 \mathrm{~K}$ and $\tau_{0}=9.2 \times 10^{-8} \mathrm{~s}$ and 8 can be described as a field-induced electro-active singleion magnet (SIM). The first observation of slow magnetic relaxation in a lanthanide coordination complex involving a TTFbased ligand was made two years earlier ${ }^{38}$ on a dinuclear complex in which significant magnetic interaction could operate. It is formed by the bridging of two Dy $(\mathrm{tta})_{3}$ units $\left(\mathrm{tta}^{-}=\right.$ 2-thenoyltrifluoroacetonate) with two tetrathiafulvalene-3pyridine- $N$-oxide ligands $\left(\mathbf{L}^{8}\right)$. In the resulting complex $\left[\mathrm{Dy}(\mathrm{tta})_{3}\left(\mathbf{L}^{8}\right)_{2}\right] \cdot 0.5 \mathrm{CH}_{2} \mathrm{Cl}_{2}$ (9, Fig. 4b), the two Dy(III) ions are in an $\mathrm{O}_{8}$ square antiprismatic coordination environment. As expected, the cyclic voltammogram displayed two one-electron oxidation waves at potentials of $0.46 \mathrm{~V}$ and $0.88 \mathrm{~V} v$ s. SCE. 9 behaved as an SMM with frequency dependence of the magnetic susceptibility below $20 \mathrm{~K}$. The temperature dependence of the relaxation time showed a thermally activated regime above $10 \mathrm{~K}$ which is characterized by $\Delta=87(1) \mathrm{K}$ and $\tau_{0}=$ $5.5 \times 10^{-7} \mathrm{~S}$ and a deviation from linearity due to a non-thermally activated regime below $10 \mathrm{~K}$ with saturation occurring within 10 s. A double-butterfly shape hysteresis loop was observed at $2 \mathrm{~K}$ and $0.5 \mathrm{~K}$ (Fig. $4 \mathrm{c}$ ). ${ }^{39}$ The fast magnetic relaxation at $H=0$ Oe is due to QTM while at 1600 Oe it is due to the crossing of the antiferromagnetically coupled energy levels which opens a new tunnelling of magnetization. Consequently the 1600 Oe field value is directly connected to the intensity of the magnetic interactions between the two Dy(III) ions. It is worth noting that due to the antiferromagnetic interactions, the magnetic relaxation did not take place in the non-magnetic ground state but within the excited states. Such magnetic behaviour associated with this kind of hysteresis loop was also observed for other antiferromagnetically coupled Dy(III) ions in dinuclear SMMs. ${ }^{40}$

Changing the interaction from antiferromagnetic to ferromagnetic is of great interest to stabilize a magnetic ground state.

Such change in the nature of magnetic interaction for TTFbased SMMs was achieved by associating the two 4,5-bis(thiomethyl)-4'-carboxylictetrathiafulvalene $\left(\mathbf{L}^{\mathbf{9}}\right)$ and 4,5-bis(thiomethyl)-4'-ortho-pyridyl- $N$-oxide-carbamoyltetrathiafulvalene $\left(\mathbf{L}^{\mathbf{1 0}}\right)$ ligands with $\mathrm{Ln}(\mathrm{tta})_{3}\left(\mathrm{H}_{2} \mathrm{O}\right)_{2}$ units. $^{41}$ Such association led to the formation of dinuclear complexes of formula $\left[\mathrm{Ln}(\mathrm{tta})_{2}\left(\mathbf{L}^{\mathbf{9}}\right)\left(\mathbf{L}^{\mathbf{1 0}}\right)\right]_{2} \cdot 2 \mathrm{CH}_{2} \mathrm{Cl}_{2}(\mathrm{Ln}=\mathrm{Dy}(\mathrm{III})(\mathbf{1 0})$ and $\mathrm{Yb}(\mathrm{III})(\mathbf{1 1}))$ in which the two lanthanide centres adopt a $D_{2 \mathrm{~d}} \mathrm{O}_{8}$ coordination sphere and are bridged by two $\mu\left(\eta_{1}, \eta_{2}\right) \mathbf{L}^{\mathbf{9}}$ while $\mathbf{L}^{\mathbf{1 0}}$ is in a terminal coordination mode (Fig. 5a). Cyclic voltammetry of $\mathbf{1 0}$ (Fig. 5b) and 11 showed two single electron waves (at $0.42 \mathrm{~V}$ and $0.57 \mathrm{~V}$ vs. SCE) corresponding respectively to the formation of the radical cation form of $\mathbf{L}^{\mathbf{9}}$ and $\mathbf{L}^{\mathbf{1 0}}$ and one double electron oxidation $(0.89 \mathrm{~V} v s$. SCE) wave attributed to the simultaneous formation of the dicationic form of $\mathbf{L}^{\mathbf{9}}$ and $\mathbf{L}^{\mathbf{1 0}}$. The $\mu\left(\eta_{1}, \eta_{2}\right)$ coordination mode of $\mathbf{L}^{\mathbf{9}}$ is suitable for observing magnetic interactions between the two lanthanide ions as shown in Fig. 5c. In fact the thermal variation of the $\chi_{\mathrm{M}} T$ product increases at low temperature, a clear sign of significant ferromagnetic interactions. The Hamiltonian depicted in eqn (2) can be used to quantify both the crystal field effect through the extended Stevens operators' technique and the intramolecular magnetic interaction:

$$
\begin{aligned}
\hat{H}= & \sum_{i=1}^{2}\left(B_{2}^{0} \widehat{\mathrm{O}_{2 i}^{0}}+B_{4}^{0} \widehat{\mathrm{O}_{4 i}^{0}}+B_{6}^{0} \widehat{\mathrm{O}_{6 i}^{0}}+B_{4}^{4} \widehat{\mathrm{O}_{4 i}^{4}}+B_{6}^{4} \widehat{\mathrm{O}_{6 i}^{4}}\right) \\
& +\beta\left(g_{J} \widehat{J_{1}}+g_{J} \widehat{J_{2}}\right) \cdot \vec{H}-J \widehat{J_{1}} \cdot \widehat{J_{2}}
\end{aligned}
$$

The best fit (Fig. 5c) for 10 was obtained with $g_{J}=4 / 3$ (fixed), $J=4.29 \times 10^{-3} \mathrm{~K}, B(0,2)=2.32 \mathrm{~K}, B(0,4)=-5.66 \times 10^{-3} \mathrm{~K}$, $B(4,4)=4.44 \times 10^{-2} \mathrm{~K}, B(0,6)=-3.46 \times 10^{-6} \mathrm{~K}$ and $B(4,6)=$ $1.03 \times 10^{-4} \mathrm{~K}$. The ground state is described by $M_{J}= \pm 15 / 2(99.9 \%)$

(a)
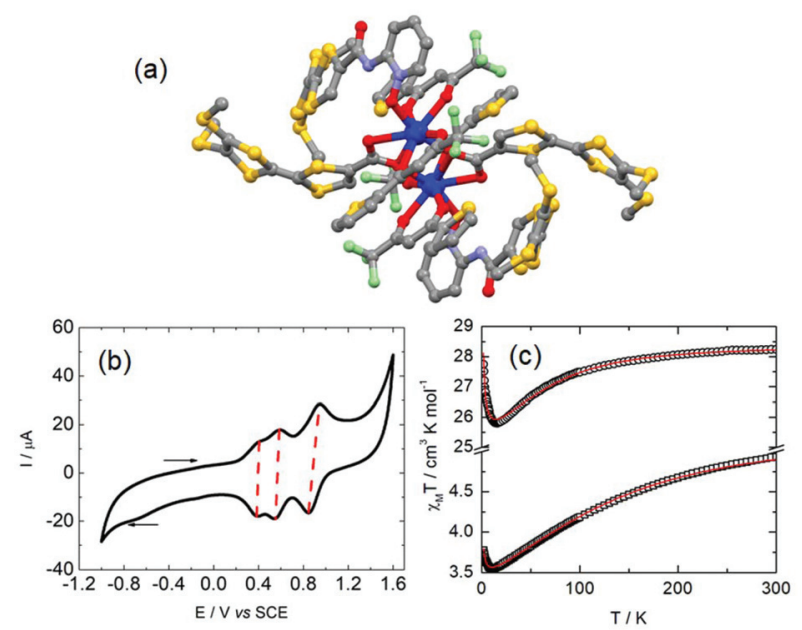

Fig. 5 (a) Molecular structure of 11. (b) Cyclic voltammograms of 10. (c) Thermal dependence of the $\chi_{M} T$ products for 10 (circles) and 11 (squares) with best fit (red lines, see main text for details). Adapted from ref. 41. 
with an almost pure first excited state $M_{J}= \pm 13 / 2$ (95\%) lying at 223 K. A simplified model considering a $D_{4 \mathrm{~d}}$ symmetry and negligible magnetic interaction was used to obtain the best fit for $\mathbf{1 1}$ (Fig. 5c). The dynamic magnetic measurements revealed an SMM behaviour in zero applied magnetic field for $\mathbf{1 0}$ with $\Delta=29 \mathrm{~K}$ and $\tau_{0}=8.6 \times 10^{-6} \mathrm{~s}$ while 11 is a field-induced SMM at 2000 Oe with $\Delta=21 \mathrm{~K}$ and $\tau_{0}=1.7 \times 10^{-6} \mathrm{~s}$. The latter ytterbium compound is remarkable because the energy splitting of the ${ }^{2} \mathrm{~F}_{7 / 2}$ multiplet state obtained from the magnetic properties could be compared to the $\mathrm{Yb}$ (III) luminescence which is experimental proof of such a splitting. 11 is one of the rare examples of redox active luminescent $\mathrm{Yb}$ (III) SMMs for which a magnetostructural correlation was done. ${ }^{42}$

A few years later, we reported another redox-active luminescent $\mathrm{Yb}$ (III) SMM. ${ }^{43}$ It was obtained by the association of the 4,5-ethylenedioxy-4',5'-bis(2-pyridyl- $N$-oxidemethylthio)tetrathiafulvalene ligand $\left(\mathbf{L}^{\mathbf{1 1}}\right)$ and the $\mathrm{Yb}(\mathrm{tta})_{3} \cdot 2 \mathrm{H}_{2} \mathrm{O}$ unit. The resulting mononuclear complex $\left[\mathrm{Yb}(\mathrm{tta})_{3}\left(\mathbf{L}^{\mathbf{1 1}}\right)\right] \cdot 2 \mathrm{CH}_{2} \mathrm{Cl}_{2} \quad$ (12) presents redox-activity with reversible single-electron oxidation potentials at $0.42 \mathrm{~V}$ and $0.87 \mathrm{~V} v$ s. SCE. Since this system crystallised in the triclinic $P \overline{1}$ space group, rotating single crystal magnetometry was performed giving access to the $g$ factors $\left(g_{x}=5.84, g_{y}=2.00\right.$ and $\left.g_{z}=1.77\right)$ in the effective spin $\frac{1}{2}$ framework. $A b$ initio calculations at the MS-CASPT2/RASSI-SO level corroborated the experimental values $\left(g_{x}=5.96, g_{y}=0.73\right.$ and $\left.g_{z}=0.33\right)$. The resulting ground state is composed of a mixing of $M_{J}= \pm 5 / 2(50 \%)$ and $M_{J}= \pm 7 / 2(34 \%)$ which are well separated from the excited states $M_{J}= \pm 7 / 2(337 \mathrm{~K}), M_{J}= \pm 3 / 2(429 \mathrm{~K})$ and $M_{J}= \pm 1 / 2(672 \mathrm{~K})$. Light irradiation at $22000 \mathrm{~cm}^{-1}$ of 12 led to an efficient sensitisation of the NIR $\mathrm{Yb}(\mathrm{III})$ emission composed of four contributions ( $0 \mathrm{~K}, 337 \mathrm{~K}, 432 \mathrm{~K}$ and $702 \mathrm{~K}$ ) perfectly in agreement with the energy splitting given by the $a b$ initio calculations. While $\mathbf{1 2}$ did not show any out-of-phase signal in a zero applied magnetic field (in agreement with the $50 \% M_{J}= \pm 5 / 2$ doublet), under 1000 Oe field it showed frequency dependence of the magnetic susceptibility below $4 \mathrm{~K}$. The temperature dependence of relaxation was fitted by an Orbach thermally activated process with $\Delta=6 \mathrm{~K}$ and $\tau_{0}=$ $1.9 \times 10^{-5} \mathrm{~s}$.

In previous lines, it was shown that redox-active lanthanide SMMs can be designed using various redox-active ligands such as tetraoxolene (section 2.1), phthalocyanine (section 2.2) and tetrathiafulvalene (section 2.3). Another strategy is to employ dyes $(\mathrm{D}-\mathrm{A})^{44}$ or triads $(\mathrm{A}-\mathrm{D}-\mathrm{A})^{45}$ in which both donor (D) and acceptor (A) are electroactive. Thus in 2012, the 4,4',7,7'-tetra-tert-butyl-2,2'-bi-1,3-benzo-dithiole-5,5',6,6'tetrone $\left(\mathbf{L}^{\mathbf{1 2}}\right) \mathrm{A}-\mathrm{D}-\mathrm{A} \operatorname{triad}^{46}$ was used as a connector between two Dy $(\mathrm{hfac})_{3}\left(\mathrm{H}_{2} \mathrm{O}\right)$ terminal units to form the dinuclear compound $\left[\mathrm{Dy}_{2}(\mathrm{hfac})_{6}\left(\mathrm{H}_{2} \mathrm{O}\right)_{2}\left(\mathbf{L}^{\mathbf{1 2}}\right)\right]$ (13) (Fig. 6).

The triad $\mathbf{L}^{\mathbf{1 2}}$ displayed a complex cyclic voltammogram with four reversible single-electron reduction waves at -0.40 , $-0.61,-1.04$ and $-2.56 \mathrm{~V}$ vs. $\mathrm{Hg} / \mathrm{HgCl}_{2}$ in $\mathrm{DMF}$ and two oxidation waves at $1.62 \mathrm{~V}$ and $1.82 \mathrm{~V}$ vs. $\mathrm{Hg} / \mathrm{HgCl}_{2}$ in chlorobenzene/MeCN. The four distinct reduction waves were attributed to the reduction of the two $o$-quinone acceptors. They are a good indication of an efficient electronic communication

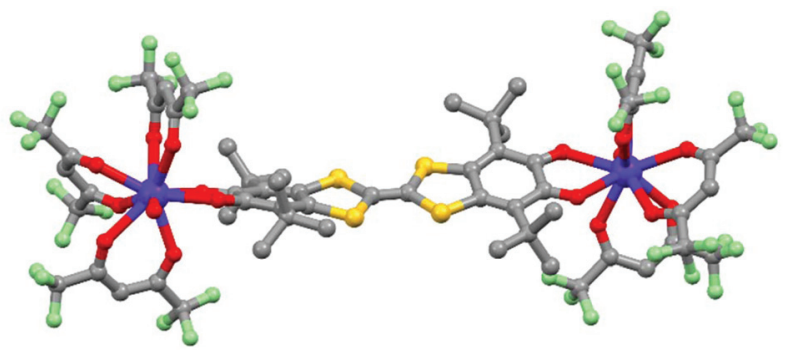

Fig. 6 Molecular structure of 13. Hydrogen atoms are omitted for clarity.

through the fused TTF. The two oxidation waves were attributed to the formation of the radical cationic and dicationic TTF species. Their large anodic shift is ascribed to the strong electron-withdrawing effect of the fused $o$-quinone acceptors. This multi electro-active compound behaved as an SMM in zero applied magnetic field with magnetic relaxation occurring through QTM $\left(\tau_{\mathrm{QTM}}=5.5 \times 10^{-4} \mathrm{~s}\right)$ and Orbach $(\Delta=15 \mathrm{~K}$ and $\tau_{0}=2.4 \times 10^{-6} \mathrm{~s}$ ) regimes.

Very recently, a semiquinone acceptor instead of quinone was stabilised in a crystalline solid state by replacing the TTF donor with a stronger donor i.e. a $p$-phenylene-extended TTF. ${ }^{47}$ The resulting 2,2'-benzene-1,4-diylbis(6-hydroxy-4,7-di-tertbutyl-1,3-benzodithiol-2-ylium-5-olate) biradical triad $\left(\mathbf{L}^{\mathbf{1 3}}\right)$ presented three one-electron reduction waves at $-0.43 \mathrm{~V},-0.57 \mathrm{~V}$ and $-0.89 \mathrm{~V} v s$. SCE and four one-oxidation waves at $0.88 \mathrm{~V}$, $1.10 \mathrm{~V}, 1.60 \mathrm{~V}$ and $1.80 \mathrm{~V} v s$. SCE. ${ }^{48}$ The first two reduction processes were attributed to the two consecutive reductions from protonated semiquinone to catechol while the third reduction process was attributed to the reduction of the central $p$-quinoid spacer. The first two oxidation waves were attributed to the successive oxidation from protonated semiquinone to quinone moieties while the two highest oxidation potentials were attributed to the formation of the radical cationic and dicationic TTF species. The multi-redox-active triad $\mathbf{L}^{\mathbf{1 3}}$ can be involved in the formation of a one-dimensional polymer when it reacted with the Dy(hfac $)_{3}$ precursor. The resulting polymer $\left\{\left[\text { Dy }(\text { hfac })_{3}\left(\mathbf{L}^{\mathbf{1 3}}\right)\right] \cdot 2 \mathrm{C}_{6} \mathrm{H}_{14}\right\}_{n}(\mathbf{1 4})$ could be described as an autoassembly of field-induced SIM with an energy barrier of $20 \mathrm{~K}$ and $\tau_{0}=2.1 \times 10^{-5} \mathrm{s.}^{49}$

Multi-redox-active lanthanide SMMs can be achieved combining two different electro-active ligands in the coordination sphere of the metal. For example J.-L. Zuo and collaborators designed a triple-decker sandwich dysprosium complex with both Pc and the Schiff base fused TTF $\left(\mathbf{L}^{7}\right)$ ligands. ${ }^{50}$ The electrochemical properties of $\left[\mathrm{Dy}_{2}(\mathrm{Pc})\left(\mathbf{L}^{7}\right)_{2}\left(\mathrm{CH}_{3} \mathrm{OH}\right)\right] \cdot 5\left(\mathrm{ClCH}_{2} \mathrm{CH}_{2} \mathrm{Cl}\right)(\mathbf{1 5})$ were driven in the oxidation region showing the reversibility of the oxidation of $\mathbf{L}^{7}$ but no data on the electro-activity of the Pc were given. 15 displayed a field-induced SMM at 3000 Oe with $\Delta=29 \mathrm{~K}$ and $\tau_{0}=3.6 \times 10^{-6} \mathrm{~s}$.

Section 2 demonstrated that lanthanide SMMs can be achieved with reversible oxidation or/and reduction of the electro-active ligand(s). Nevertheless until this point of the 


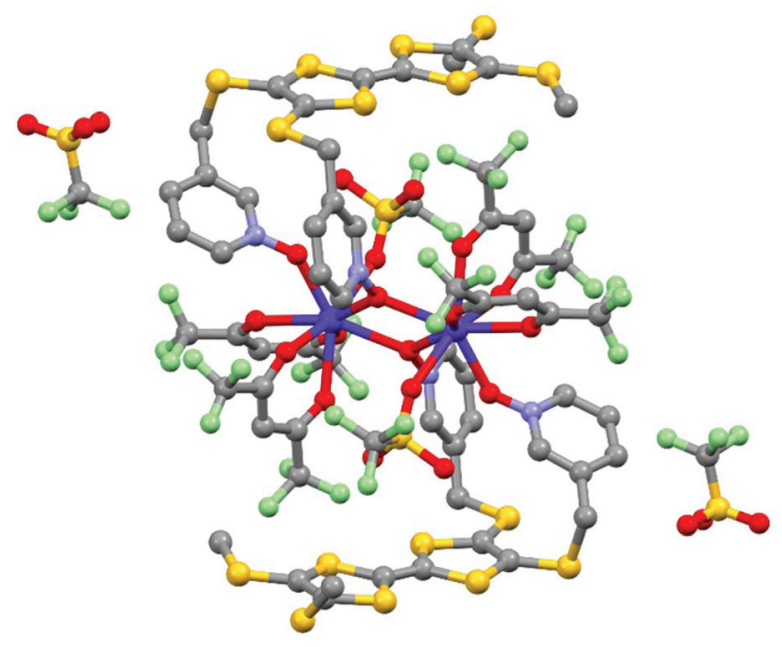

Fig. 7 Molecular structure of 16 . Hydrogen atoms and solvent molecule of crystallization are omitted for clarity. Adapted from ref. 51.

review, no oxidized or reduced species were isolated in the solid state. The last example of this section relates, to the best of our knowledge, the unique example of a lanthanide coordination complex involving the radical cation oxidation state of the TTF-based ligand and SMM behaviour. This complex was isolated by the galvanostatic oxidation of a mixture of 4,5 -bis (3-pyridyl- $N$-oxidemethylthio)-4', $5^{\prime}$-methyldithio-tetrathiafulvalene ligand $\left(\mathbf{L}^{\mathbf{1 4}}\right)$ and $\mathrm{Dy}(\mathrm{hfac})_{3} \cdot 2 \mathrm{H}_{2} \mathrm{O}$ in the presence of the $\mathrm{TBASO}_{3} \mathrm{CF}_{3}$ electrolyte in $\mathrm{CH}_{2} \mathrm{Cl}_{2} \cdot{ }^{51}$ This technique allowed the isolation of single crystals of a dinuclear sample of formula $\left[\mathrm{Dy}(\mathrm{hfac})_{2}\left(\mathrm{SO}_{3} \mathrm{CF}_{3}\right)\left(\left(\mathbf{L}^{\mathbf{1 4}}\right)^{\bullet+}\right)\right]_{2}\left(\mathrm{CF}_{3} \mathrm{SO}_{3}\right)_{2} \cdot 2 \mathrm{CH}_{2} \mathrm{Cl}_{2} \quad$ (16) (Fig. 7). The X-ray structure of $\mathbf{1 6}$ consisted of a dinuclear complex in which the two Dy(III) ions are bridged by two 3-Py- $N$-oxide arms. The fully oxygenated coordination sphere is completed by one terminal 3-Py- $N$-oxide arm, two hfac ${ }^{-}$anions and one sulfonate anion. Two non-coordinated sulfonate anions were identified leading to a radical cation oxidation state for the two $\mathbf{L}^{\mathbf{1 4}}$ ligands to assume the electroneutrality of the sample. The radical cation form of $\mathbf{L}^{\mathbf{1 4}}$ was confirmed by both EPR measurements on a single crystal $(g=2.00798)^{52}$ and absorption spectroscopy with the appearance of an intra-ligand charge transfer band at very low energy. ${ }^{53} 16$ behaved as a field-induced SMM at 800 Oe with $\Delta=12 \mathrm{~K}$. Unfortunately, the crystal packing did not allow electronic conductivity and 16 was described as an insulator.

\section{Redox switching of single- molecule magnet behaviour}

The aim of section 3 is to show the readers how the magnetic properties i.e. the SMM behaviour can be modulated in function of the oxidation state of the ligand or the metal.

\subsection{Ligand-centred redox-activity}

The first examples presented in section 2 were based on the tetraoxolene ligand (complexes 1 and 2) but the SMM behav- iour was studied only for the closed-shell bridges. ${ }^{54}$ Interest for studying open-shell ligand-based lanthanide compounds comes from the high-performance of the $\mathrm{N}_{2}{ }^{3-}$ radical-bridged lanthanide dinuclear complexes in which the exchange interactions vanished the efficiency of the QTM giving rise to a blocking temperature as high as $14 \mathrm{~K}^{55}$ Then several lanthanide SMMs were successfully obtained with the implication of radical bridges. ${ }^{56}$ The first example of lanthanide complexes involving a tetraoxolene radical was published in 2018 by J. van Slageren and collaborators. ${ }^{57}$ It was obtained by the chemical reduction of $\mathbf{1}$ with cobaltocene leading to the dinuclear complex $\left(\mathbf{1}^{-}\right)\left(\mathrm{CoCp}_{2}\right)$ in which tetraoxolene is in its tri-anionic radical form. While $\mathbf{1}$ did not show any out-of phase component of the magnetic susceptibility under a zero applied magnetic field, its reduced form $\left(\mathbf{1}^{\circ}-\right)\left(\mathrm{CoCp}_{2}\right)$ did (Table 1). The modification of the magnetic properties was mainly attributed to the presence of ferromagnetic interactions between the radical bridge and the Dy(III) ion (determined equal to $6 \mathrm{~K}$ in the Gd(III) analogue). In other words, the SMM behaviour in the zero magnetic field of $\mathbf{1}$ was switched on after single-electron reduction.

Similar modulation of the SMM behaviour due to the reduction of a closed-shell ligand to a radical ligand was observed for the first time a year before by the group of K. R. Dunbar. ${ }^{58}$ 3,6-Bis(2-pyridyl)-1,2,4,5-tetrazine $\left(\mathbf{L}^{\mathbf{1 5}}\right)$ was selected for its easily accessible reduction potential and to bridge two $\left[\mathrm{Dy}(\mathrm{tmhd})_{3}\right]$ units (tmhd $=$ 2,2,6,6-tetramethyl-3,5heptane dionate) leading to the $\left[\left(\text { Dy }(\text { tmhd })_{3}\right)_{2}\left(\mathbf{L}^{\mathbf{1 5}}\right)\right](\mathbf{1 7}) \mathrm{di}$ nuclear compound. 17 displayed a thermally independent outof-phase signal of magnetic susceptibility which has been attributed to magnetic relaxation through a QTM process. After the single reduction of 17 with $\mathrm{Cp}_{2} \mathrm{Co}$, the resulting $\left[\mathrm{Cp}_{2} \mathrm{Co}\right]\left[\left(\mathrm{Dy}(\mathrm{tmhd})_{3}\right)_{2}\left(\mathbf{L}^{\mathbf{1 5}}\right)^{\cdot-}\right]\left(\mathrm{Cp}_{2} \mathrm{Co}\right)(\mathbf{1 7})$ displayed a frequency dependence of the $\chi^{\prime \prime}{ }_{\mathrm{M}}$ component allowing the extraction of the energy barrier $\Delta=12.4 \mathrm{~K}$ and time constant $\tau=1.68 \times 10^{-5} \mathrm{~S}$ for an Orbach process (Table 1). The presence of $S=\frac{1}{2}$ centred on the bridging ligand led to magnetic interactions with the two Dy(III) ions that efficiently suppress the QTM observed for 17.

The most known redox-active ligands in molecular magnetism are the phthalocyanine $(\mathrm{Pc})$ derivatives since the $[\mathrm{PcTb}]^{-}$ anion was the first mononuclear lanthanide SMM reported. The Pc ligand can be easily reduced and oxidized as shown in section 2.2. Thus Ishikawa and collaborators compared the magnetic properties of the $\left[\left(\mathbf{L}^{\mathbf{1 6}}\right)_{2} \mathrm{~Tb}\right]^{-}$anion $(\mathbf{1 8})\left[n \mathrm{Bu}_{4} \mathrm{~N}\right]$ $\left(\mathbf{L}^{\mathbf{1 6}}=2,3,9,10,16,17,23,24\right.$-octaethoxyphthalocyanine $)$ with those of the $\left[\left(\mathbf{L}^{\mathbf{1 6}}\right)_{2} \mathrm{~Tb}\right]^{+}$cation $(\mathbf{1 8})\left[\mathrm{SbCl}_{6}\right]$, both obtained from the reduction and oxidation of the neutral $\left[\left(\mathbf{L}^{\mathbf{1 6}}\right)_{2} \mathrm{~Tb}\right],{ }^{59}$ respectively. ${ }^{60}$ While the reduced form of 18 showed temperature dependence of the $\chi^{\prime \prime}{ }_{\mathrm{M}}$ component until $40 \mathrm{~K}$, the oxidised form displayed it until $52 \mathrm{~K}$.

Consequently the energy barrier of $(\mathbf{1 8})\left[\mathrm{SbCl}_{6}\right]$ is found to be $8 \%$ greater than the one of $(18)\left[n \mathrm{Bu}_{4} \mathrm{~N}\right](\Delta=791 \mathrm{~K})$ (Table 1). This difference in the energy barrier was attributed to the compression of the coordination sphere after oxidation of the $\mathbf{L}^{\mathbf{1 6}}$ ligand leading to a stronger crystal field. 


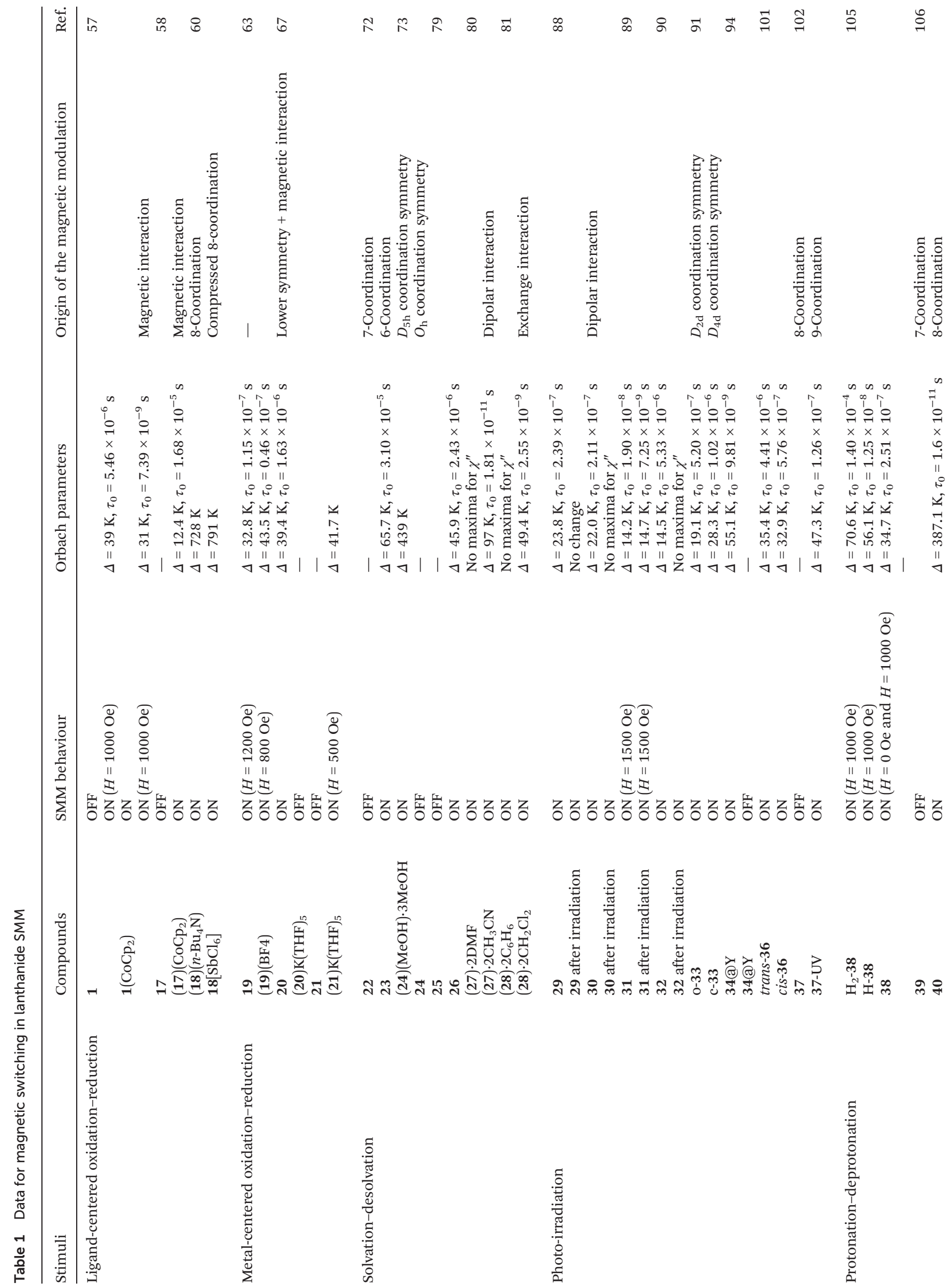



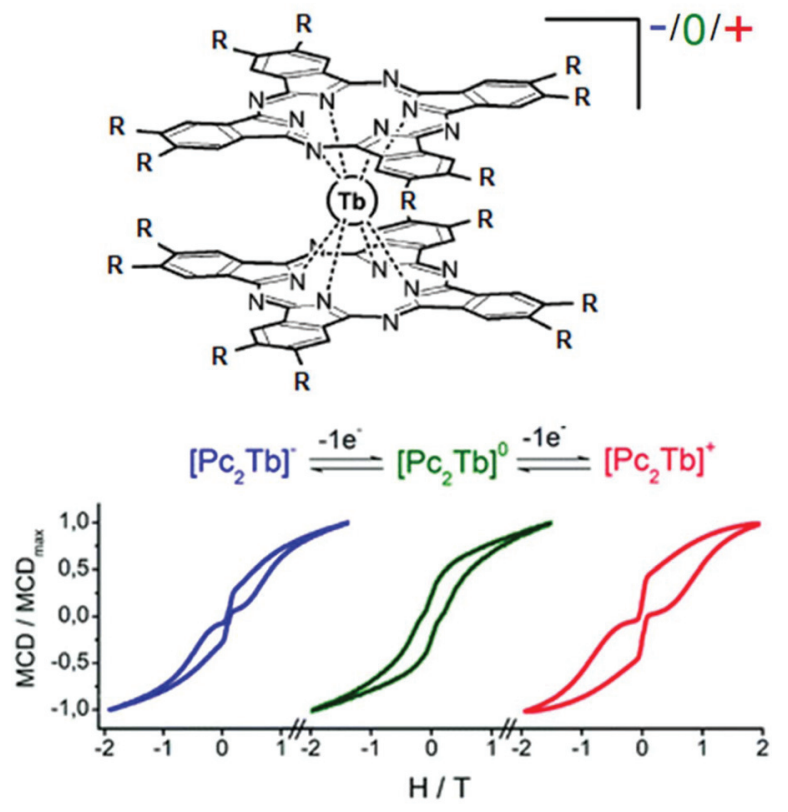

Fig. 8 Molecular structure of 18. Hydrogen atoms and solvent molecule of crystallization are omitted for clarity. Adapted from ref. 60 and 61.

Few years later, J. Veciana and collaborators probed the magnetic bistability of the three stable oxidation states of the same derivative (Fig. 8). ${ }^{61}$ For ease of isolation and stability of the samples, it appeared that magnetic circular dichroism (MCD) spectroscopy was the most powerful tool to probe the magnetic hysteresis, as already demonstrated for $\mathrm{Mn}_{12}$ SMMs. ${ }^{62}$ Both reduced and oxidised forms displayed butterflyshape hysteresis with a greater coercive field for $(\mathbf{1 8})^{+}$than (18) $)^{-}$(Fig. 8) in agreement with what was observed in alternating current magnetic measurements. The neutral derivative (18) displayed an open hysteresis loop which remains open in the zero magnetic field (Fig. 8) due to a less efficient QTM. The observation of coercive field at $H=0$ Oe is probably due to the association of $S=\frac{1}{2}$ with the $\mathrm{Tb}$ (III) ion.

\subsection{Metal-centred redox-activity}

The redox activity can also be carried by a $3 \mathrm{~d}$ or $4 \mathrm{~d}$ transition metal associated with the lanthanide. One example was obtained by the association of a ruthenium carbon-rich complex with the Dy $(\mathrm{tta})_{3}$ unit. $^{63}$ The ruthenium moiety brings the redox activity and it has already proved its ability to switch conductivity, ${ }^{64}$ non-linear optics ${ }^{65}$ or luminescence. ${ }^{66}$ It was decorated with 2,2'-bipyridine to coordinate the lanthanide centre. The cyclic voltammogram of trans$\left[\left(\mathrm{PhC} \equiv \mathrm{C}(\mathrm{dppe})_{2} \mathrm{RuC} \equiv \mathrm{C}-\right.\right.$ bipyridyl $\left.)\left(\mathrm{Dy}(\mathrm{tta})_{3}\right)\right](19)(\mathrm{dppe}=1,2-$ bis(diphenylphosphino)ethane) showed a reversible singleelectron process at $0.062 \mathrm{~V} v s$. $\mathrm{Fc} / \mathrm{Fc}^{+}$allowing the oxidation of $\mathrm{Ru}(\mathrm{II})$ in $\mathrm{Ru}(\mathrm{III})$ in the presence of acetylferrocenium tetrafluoroborate at $-60{ }^{\circ} \mathrm{C}$ under argon leading to $(19)\left(\mathrm{BF}_{4}\right)$. Both neutral 19 and radical cations $(19)\left(\mathrm{BF}_{4}\right)$ behaved as fieldinduced SMMs with magnetic relaxation through an Orbach process which is characterized by $\Delta=32.8 \mathrm{~K}$ and $\tau_{0}=$ $1.15 \times 10^{-7} \mathrm{~s}(H=1200 \mathrm{Oe})$ and $\Delta=43.5 \mathrm{~K}$ and $\tau_{0}=0.46 \times 10^{-7} \mathrm{~s}$ $(H=800$ Oe $)$ respectively. The oxidation of the ruthenium carbon-rich complex induced an increase of the energy barrier of $30 \%$ and the magnetic relaxation of $(19)\left(\mathrm{BF}_{4}\right)$ was measured forty times slower than 19 at $2 \mathrm{~K}$ (Table 1). The enhancement of the magnetic performances should be attributed to both the $S=\frac{1}{2}$ carried by the ruthenium carbon-rich moiety and the structural changes around the Dy(III) ion after oxidation. The role of the intermolecular interaction was not evaluated for this system. It is worth noting that the reversibility of oxidation was proved by absorption spectroscopy.

The second example is made from the reaction between two equivalents of $\left[\mathrm{K}_{2}\left(\mathrm{OEt}_{2}\right)\right] \mathrm{fc}\left[\mathrm{NSi}(t-\mathrm{Bu}) \mathrm{Me}_{2}\right]_{2}$ and one equivalent of $\mathrm{LnI}_{3}$ leading to the trinuclear complexes $\mathrm{K}(\mathrm{THF})_{5}\left[\mathrm{Ln}\left(\mathrm{fc}\left[\mathrm{NSi}(t-\mathrm{Bu}) \mathrm{Me}_{2}\right]_{2}\right)_{2}\right]\left(\operatorname{Ln}(\mathrm{III})=\mathrm{Dy}(\mathbf{2 0}) \mathrm{K}(\mathrm{THF})_{5}\right.$ and Er (21)K(THF) $)_{5}$ ) (Fig. 8). ${ }^{67}$ These two compounds could be oxidised by iodine to generate the mixed valence $\mathrm{Fe}(\mathrm{III}) / \mathrm{Fe}$ (II) $\left[\mathrm{Ln}\left(\mathrm{fc}\left[\mathrm{NSi}(t-\mathrm{Bu}) \mathrm{Me}_{2}\right]_{2}\right)_{2}\right](\operatorname{Ln}(\mathrm{III})=$ Dy (20) and Er (21)) (Fig. 9). Starting from the Dy(III) analogue, (20)K(THF) $)_{5}$ displayed a zero magnetic field SMM behaviour with a magnetic relaxation which followed QTM, Raman and Orbach processes. Eqn (1) was used to determine the parameters ${ }^{68}$ giving the best fit of the temperature dependence of the magnetic relaxation $\left(\tau_{\mathrm{QTM}}=5.03 \times 10^{-4} \mathrm{~s}, C=0.08 \mathrm{~s}^{-1} \mathrm{~K}^{-n}\right.$ with $n=5$ and $\Delta=$ $\left.39.3 \mathrm{~K}, \tau_{0}=1.63 \times 10^{-6} \mathrm{~s}\right)$. Single oxidation of $(20) \mathrm{K}(\mathrm{THF})_{5}$ in 20 switched OFF the SMM behaviour in the zero applied magnetic field. Under an optimal applied magnetic field of 1000 Oe, both $(20) \mathrm{K}(\mathrm{THF})_{5}$ and 20 presented field-induced SMM behaviour but $\mathbf{2 0}$ highlighted a much faster magnetic relaxation than $(\mathbf{2 0}) \mathrm{K}(\mathrm{THF})_{5}$. The magnetic relaxation involved a complex combination of relaxation processes i.e. direct, QTM, Raman and Orbach regimes. ${ }^{68}$ The energy barrier of (20) $\mathrm{K}(\mathrm{THF})_{5}$ was evaluated to be $66.2 \mathrm{~K}$ which is higher than that

(a)
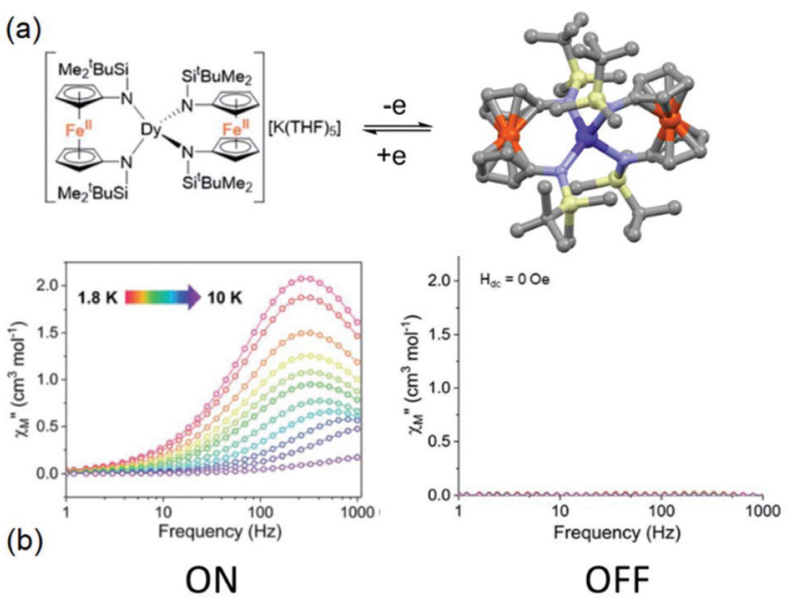

Fig. 9 (a) Molecular structures of $(20) \mathrm{K}(\mathrm{THF})_{5}$ (left) and its oxidised form 20 (right). (b) Frequency dependence of the magnetic susceptibility for $(20) K(T H F)_{5}$ (left) and 20 (right) highlighting the ON and OFF SMM behaviour respectively. Colour code: silicon: light yellow and iron: orange. Adapted from ref. 67. 
of the oxidised sample $20(\Delta=39.1 \mathrm{~K})$. Another difference is the presence of remaining QTM at 1000 Oe for $20\left(\tau_{\mathrm{OTM}}=\right.$ $\left.8.77 \times 10^{-4} \mathrm{~s}\right)$.

Concerning the $\operatorname{Er}(\mathrm{III})$ analogue, any of the two $(\mathbf{2 1}) \mathrm{K}$ $(\mathrm{THF})_{5}$ and 21 samples behaving as SMMs in the zero magnetic field while applying a moderate field of 500 Oe to vanish the QTM allowed the observation of an out-of-phase component of the magnetic susceptibility for $(21) \mathrm{K}(\mathrm{THF})_{5}$ while 21 did not show any SMM behaviour. The dynamic parameters of the four processes involved in the magnetic relaxation were determined with among others an energy barrier of $41.7 \mathrm{~K}$. As already observed for the Dy(III) analogue, the single-electron oxidation switched OFF the field-induced SMM for the Er(III) derivative. It is worth noting that this remains the unique example until now of redox-switching of an $\operatorname{Er}(\mathrm{III}) \mathrm{SMM}$ behaviour.

The authors attributed the significant deterioration of the magnetic performances after single electron oxidation to the faster QTM in 20/21 than for $(\mathbf{2 0 / 2 1}) \mathrm{K}(\mathrm{THF})_{5}$ due to both the lower symmetry around the $\operatorname{Ln}(\mathrm{III})$ ion and the paramagnetic Fe(III) $\left(S=\frac{1}{2}\right)$. The strong electronic communication between the two Fe(II) and Fe(III) ions has been demonstrated by (i) a large comproportionation constant due to an important difference of Fe-centred oxidation potentials which is in agreement with a Robin and Day class II classification (mixed valence compound), ${ }^{69}$ (ii) Mössbauer spectroscopy because the $\mathrm{Fe}(\mathrm{III})$ site is quadrupole split instead of showing a singlet ${ }^{70}$ and (iii) UV-vis-NIR spectroscopy with the observation of an intervalence charge transfer transition at $1050 \mathrm{~nm} .^{71}$

\section{Solvato switching of single- molecule magnet behaviour}

Magnetic modifications can be induced by other stimuli such as solvation/desolvation, light irradiation, and protonation/ deprotonation. The next sections will show the most representative examples of magnetic switches under these various stimuli.

The year 2013 has been very rich on the topic of solvato-magnetic switches. The dinuclear compound $\left\{\left[\mathrm{Dy}\left(\mathrm{H}_{2} \mathrm{O}\right)_{2}\left(\mathrm{CH}_{3} \mathrm{COCH}_{3}\right)\right]_{2}\left(\gamma-\mathrm{SiW}_{10} \mathrm{O}_{36}\right)_{2}\right\}^{10-} \quad$ (22) in which the two Dy(III) ions were in a distorted monocapped trigonal prism can be reversibly transformed in the $\left[\mathrm{Dy}_{2}(\mu-\mathrm{OH})_{2}\left(\gamma-\mathrm{SiW}_{10} \mathrm{O}_{36}\right)_{2}\right]^{12-}$ dinuclear compound (23) in the presence of the TBAOH base. ${ }^{72}$ In the latter compound, the two Dy(III) ions are bridged by two hydroxyl anions and now are in a distorted trigonal prism environment. The recovery of 22 from 23 was possible in the presence of $\mathrm{HNO}_{3}$ acid in acetone/acetonitrile $/ \mathrm{H}_{2} \mathrm{O}$. In the dynamic magnetic point of view, 22 did not show any significant SMM behaviour while 23 behaved as an SMM characterized by a thermally dependent regime at high temperature $\left(\Delta=65.7 \mathrm{~K}\right.$ and $\left.\tau_{0}=3.11 \times 10^{-7} \mathrm{~s}\right)$ and QTM at low temperature. The Gd(III) analogue of $\mathbf{2 3}$ allowed the determination of the antiferromagnetic interaction between the lanthanide ions through the hydroxyl anion but since the diluted samples behaved as the non-diluted ones the authors concluded that the magnetic interaction plays a minor role in the magnetic switching between 22 and 23. Then the SMM switching was attributed to the change in coordination sphere symmetry when solvation/desolvation took place.

The second example of the same year was published by M.-L. Tong and collaborators. The ligand 2,2',2"-(((nitrile-tris (ethane-2,1-diyl))tris(azanediyl))tris(methylene))tris-(4-bromophenol) ( $\mathbf{L}^{\mathbf{1 7}}$ ) was used to react with both $\mathrm{Zn(II)}$ and Dy(III) (2:1) giving rise to $\left[\mathrm{Zn}_{2} \mathrm{Dy}\left(\mathbf{L}^{\mathbf{1 7}}\right)_{2}(\mathrm{MeOH})\right] \mathrm{NO}_{3} \cdot 3 \mathrm{MeOH} \cdot \mathrm{H}_{2} \mathrm{O}(\mathbf{2 4})$ $(\mathrm{MeOH}) \cdot 3 \mathrm{MeOH}$ (Fig. 10). ${ }^{73}$ Both coordinated and uncoordinated $\mathrm{MeOH}$ molecules can be removed by exposure to air in a single-crystal-to-single-crystal transformation giving the compound (24) (Fig. 10). (24)(MeOH).3MeOH showed SMM behaviour without applied magnetic field while 24 did not. In the high-temperature regime, the relaxation of magnetization for 24 follows an Orbach process with $\Delta=439 \mathrm{~K}$ in perfect agreement with the calculated $a b$ initio value of $425 \mathrm{~K}$.

The high energy barrier for $(\mathbf{2 4})(\mathrm{MeOH}) \cdot 3 \mathrm{MeOH}$ was attributed to both the quasi- $D_{5 \mathrm{~h}}$ symmetry of the Dy(III) coordination environment and the two coordinating axial phenoxyl groups. ${ }^{74}$ In fact the computational approach showed that the ground state Kramers doublet in $D_{5 \mathrm{~h}}$ symmetry is perfectly axial. After the single-crystal-to-single-crystal transformation the SMM behaviour is quenched due to the quasi- $O_{\mathrm{h}}$ symmetry of the Dy(III) coordination environment in $\mathbf{2 4}$ leading to an efficient QTM. Thus a magnetic field of 1200 Oe should be applied to observe an out-of-phase component of the magnetic susceptibility. The Arrhenius plot involved both direct and Raman processes while the Orbach process was determined to be negligible. Both previous similar examples in the literature $^{75}$ and the discrepancy between the experimental (64 K) and calculated (>400 K) "energy barrier" are in agreement with a negligible Orbach contribution in the magnetic relaxation processes. ${ }^{76}$ Finally the difference in magnetic performances can be visualized by measuring the hysteresis loop at $0.03 \mathrm{~K}$
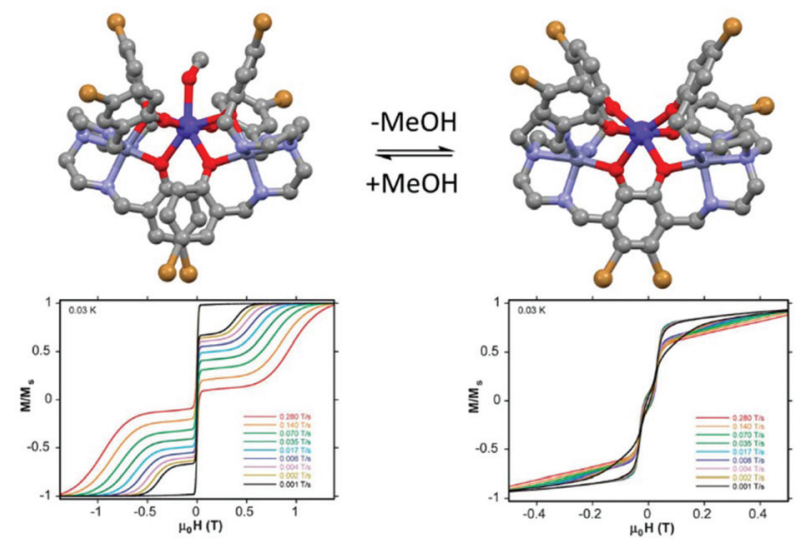

Fig. 10 Molecular structures of $(24)(\mathrm{MeOH}) \cdot 3 \mathrm{MeOH}$ with its hysteresis loop at $0.03 \mathrm{~K}$ (left part) and its methanol free analogue (24) with its hysteresis loop at $0.03 \mathrm{~K}$ (right part). Colour code: bromide: brown. Adapted from ref. 73. 
for single crystals of both (24)(MeOH) $3 \mathrm{MeOH}$ and 24 using a micro-SQUID magnetometer. ${ }^{77}$ While $(\mathbf{2 4})(\mathrm{MeOH}) \cdot 3 \mathrm{MeOH}$ showed an open hysteresis until $11 \mathrm{~K}$, the remnant magnetization is negligible for $\mathbf{2 4}$ (Fig. 10).

The third example is based on a metal-organic framework (MOF) reported in 2006 by Qiu and collaborators. ${ }^{78}$ $\left[\operatorname{Dy}\left(\mathbf{L}^{18}\right)\left(\mathrm{H}_{2} \mathrm{O}\right)\right] \cdot \operatorname{DMF}(25)$ (where $\mathbf{H}_{3} \mathbf{L}^{18}=1,3,5$-benzenetricarboxylic acid and DMF $=N, N^{\prime}$-dimethylformamide) was obtained by mixing the nitrate salt of Dy(III) and $\mathbf{H}_{3} \mathbf{L}^{18}$ in DMF/EtOH followed by the successive addition of dibutylamine and nitric acid. The Dy(III) ion is seven-coordinated in a pentagonal-bipyramidal prismatic surrounding. The coordinated water and guest DMF molecules can be removed by calcination at $240{ }^{\circ} \mathrm{C}$ for $12 \mathrm{~h}$ in a single-crystal-to-singlecrystal transformation. The resulting $\left[\operatorname{Dy}\left(\mathbf{L}^{\mathbf{1 8}}\right)\right]$ (26) MOF revealed Dy(III) ions in a distorted trigonal prismatic environment after removing the coordinated water molecule. 25 can be reversibly recovered by single-crystal-to-single-crystal transformation by immersion of 26 in a $\mathrm{H}_{2} \mathrm{O} /$ DMF mixture. ${ }^{79} 25$ did not show any SMM behaviour in zero and non-zero applied magnetic fields while after removing the guest solvent molecules, 26 behaved as an SMM in both zero and 1000 Oe applied magnetic fields. Both thermally dependent and independent magnetic relaxation processes were present. The high temperature Orbach regime fit gave an energy barrier of $45.9 \mathrm{~K}$ and $\tau_{0}=2.43 \times 10^{-6} \mathrm{~s}$. The switch OFF of the SMM behaviour after desolvation was attributed to the change in the coordination surrounding symmetry.

In 2015, another system based on a MOF was published by J. R. Long and collaborators. ${ }^{80}$ This MOF of formula $\left[\mathrm{Dy}_{2}\left(\mathbf{L}^{19}\right)_{4}\left(\mathrm{NO}_{3}\right)_{2}\right] \cdot 2 \mathrm{DMF}$ (27).2DMF was elaborated by the solvothermal reaction of nitrate salt of Dy(III), $\mathbf{L}^{\mathbf{1 9}}\left(\mathbf{L}^{\mathbf{1 9}}=\right.$ isonicotinic acid $N$-oxide) in DMF. The X-ray structure determined from single-crystal revealed the formation of a 3D network in which the nods are formed by dinuclear Dy(III) units and the linkers between the nods are the $\mathbf{L}^{\mathbf{1 9}}$ ligands. The pores are filled by the guest DMF molecules. (27)-2DMF could be converted into (27) $\cdot 2 \mathrm{CH}_{3} \mathrm{CN}$ by single-crystal-to-single-crystal transformation soaking (27).2DMF in $\mathrm{CH}_{3} \mathrm{CN}$ and vice versa. While (27)-2DMF displayed slow magnetic relaxation at very high frequencies $(10 \mathrm{kHz})$ through a direct mechanism, (27) $\cdot 2 \mathrm{CH}_{3} \mathrm{CN}$ displayed an SMM behaviour at much lower frequency through a multiple relaxation process. The plot of $\ln (\tau)$ versus $T^{-1}$ was fitted using eqn (2) with an Orbach regime at high temperature $\left(\Delta=97 \mathrm{~K}\right.$ and $\left.\tau_{0}=1.81 \times 10^{-11} \mathrm{~s}\right)$ (Table 1$)$, Raman regime at intermediate temperature $\left(C=0.0476 \mathrm{~s}^{-1}\right.$ $\left.\mathrm{K}^{-5.71}, n=5.71\right)$ and QTM at low temperature $\left(\tau_{\mathrm{QTM}}{ }^{-1}=26.3\right.$ $\mathrm{s}^{-1}$ ). The most fundamental difference in the three previous examples of this section is that the guest solvent molecules are not coordinated to the Dy(III) centres and so the single-crystalto-single-crystal transformation did not induce change in the nature of the lanthanide surrounding. In order to give an explanation to the observed magnetic modulation in function of the nature of the guest solvent molecules, the authors evaluated the dipolar interactions (which have been calculated much stronger than the exchange interactions) on the basis of ab initio calculations. Thus the tunnelling gap $\Delta_{\text {tun }}$ and dipolar applied magnetic field $H_{\text {dip }}\left(\Delta_{\text {tun }}=1 / 2 g_{x, y} \mu_{\mathrm{B}} H_{\text {dip }}\right)$ were found to be respectively equal to $10^{-3} \mathrm{~K}$ and $10^{-2} \mathrm{~K}$, and $100 \mathrm{mT}$ and $90 \mathrm{mT}$ for $(27) \cdot 2 \mathrm{CH}_{3} \mathrm{CN}\left(J_{\text {dip }}=3.04 \mathrm{~K}\right)$ and $(27) \cdot 2 \mathrm{DMF}\left(J_{\text {dip }}=\right.$ $2.6 \mathrm{~K}$ ) leading to magnetic relaxation 100 times slower for the former than for the latter (QTM $\sim \Delta_{\text {tun }}{ }^{2}$ ). This system is the first example of SMM behaviour modulation by tuning the dipolar interaction depending on the nature of the guest noncoordinated solvent molecules.

The second example of magnetic modulation by changing the lattice solvent nature was published in 2017 by J.-L. Zuo and collaborators. ${ }^{81}$ The benzene lattice of the $\left[\mathrm{Er}_{2}(\text { thd })_{4} \mathrm{Pc}\right] \cdot 2 \mathrm{C}_{6} \mathrm{H}_{6}(\mathbf{2 8}) \cdot 2 \mathrm{C}_{6} \mathrm{H}_{6}$ dinuclear compound (Hthd $=2,2,6,6$-tetramethylheptanedione) could be reversibly exchanged by immersion in dichloromethane to give $\left[\mathrm{Er}_{2}(\mathrm{thd})_{4} \mathrm{Pc}\right] \cdot 2 \mathrm{CH}_{2} \mathrm{Cl}_{2}$ (28) $\cdot 2 \mathrm{CH}_{2} \mathrm{Cl}_{2}$ by single-crystal-to-singlecrystal transformation (Fig. 11).

Except for the solvent lattice, the structure of the complex $\left[\operatorname{Er}_{2}(\text { thd })_{4} \mathrm{Pc}\right]$ is very similar in the two solvates. Ab initio calculations gave very similar axial anisotropy for both compounds. Nevertheless dynamic magnetic measurements clearly showed that magnetic relaxation for $(\mathbf{2 8}) \cdot 2 \mathrm{C}_{6} \mathrm{H}_{6}$ is faster than that for (28) $\cdot 2 \mathrm{CH}_{2} \mathrm{Cl}_{2}$. In fact reasonable parameters could be obtained only for (28) $\cdot 2 \mathrm{CH}_{2} \mathrm{Cl}_{2}$. The best fit of the thermal dependence of magnetic relaxation was obtained for a combination of Orbach $\left(\Delta=49.4 \mathrm{~K}, \tau_{0}=2.55 \times 10^{-9} \mathrm{~s}\right)$ (Table 1), direct $(A=$ $6.01 \times 10^{-4} \mathrm{~s}^{-2} \mathrm{Oe}^{-2}$ with $\left.m=2\right)$ and Raman $\left(C=1.88 \mathrm{~s}^{-1} \mathrm{~K}^{-n}\right.$, $n=5.19)$ processes. The thermal variation of the magnetic susceptibilities was fitted using POLY-ANISO ${ }^{82}$ and considering the magnetic interaction as $J_{\text {total }}=J_{\text {exchange }}+J_{\text {dipolar. }}$. The dipolar interactions were found to be ferromagnetic and very close in both solvates while the exchange interactions were found to be antiferromagnetic and stronger in $(28) \cdot 2 \mathrm{C}_{6} \mathrm{H}_{6}$ than in (28) $\cdot 2 \mathrm{CH}_{2} \mathrm{Cl}_{2}$. Consequently, $J_{\text {total }}$ was calculated to be equal to $9.11 \mathrm{~K}$ and $2.92 \mathrm{~K}$ in $(28) \cdot 2 \mathrm{C}_{6} \mathrm{H}_{6}$ and $(28) \cdot 2 \mathrm{CH}_{2} \mathrm{Cl}_{2}$ respectively and used as the main reason for the drastic difference in magnetic relaxation.

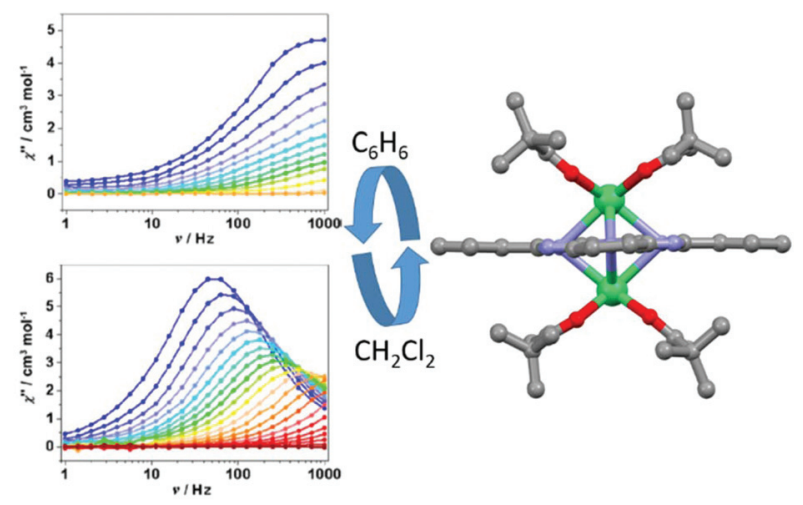

Fig. $11 \mathrm{X}$-ray structure of complex 28 (right part) and out-of-phase component of magnetic susceptibility for both benzene $\left(\mathrm{C}_{6} \mathrm{H}_{6}\right)$ and dichloromethane $\left(\mathrm{CH}_{2} \mathrm{Cl}_{2}\right)$ solvent lattices. Colour code: erbium: green. Adapted from ref. 81 . 


\section{Photo-switching of single- molecule magnet behaviour}

Another efficient applied external stimulus is light irradiation when the systems incorporate photochromic moieties.

\subsection{Dithienylethene (DTE) based-photochromic ligands}

One of the most famous photochromic moieties is undoubtedly dithienylethene (DTE). DTE derivatives are widely used because they are thermally stable and their fatigue-resistant performances are remarkable in both the solution and solidstate. ${ }^{83} \mathrm{UV}$ and visible light irradiation led to the reversible isomerization of the DTE between ring-opened and ring-closed isomers, respectively. ${ }^{84}$ The DTE core can be functionalised by chemical groups able to coordinate metal ions. ${ }^{85}$

One of the first examples incorporating the coordination of a DTE derivative with lanthanide ions was published in 2011 by $\mathrm{M}$. Yamashita and $\mathrm{M}$. Irie ${ }^{86}$ combining the well-known $\operatorname{SMM}\left[\mathrm{CuTb}\left(\mathbf{L}^{20}\right)\left(\mathrm{NO}_{3}\right)_{3}\right]\left(\mathbf{L}^{20}=1,3-b i s((3-m e t h o x y s a l i c y l i d e n e)-\right.$ amino)propane $)^{87}$ and 1,2-bis(5-carboxyl-2-methyl-3-thienyl) perfluorocyclopentene $\left(\mathbf{L}^{21}\right){ }^{88}$ Two different systems could be isolated depending on if the open form $\left(\mathbf{o}-\mathbf{L}^{\mathbf{2 1}}\right)$ or closed form (c- $\left.\mathbf{L}^{21}\right)$ of the DTE ligand is used. o- $\mathbf{L}^{21}$ led to the formation of a tetranuclear ring-like structure of formula $\left[\mathrm{Cu}_{2} \mathrm{~Tb}_{2}\left(\mathbf{L}^{20}\right)_{2}\left(\mathbf{o}-\mathbf{L}^{2 \mathbf{2 1}}\right)_{2}\left(\mathrm{NO}_{3}\right)_{2}\right] \cdot 2(n-\mathrm{BuOH}) \quad$ (29) while $\mathbf{c}-\mathbf{L}^{\mathbf{2 1}}$ led to the formation of a mono-dimensional ladder-type structure of formula $\left\{\left[\left(\mathrm{CuTb}\left(\mathbf{L}^{\mathbf{2 0}}\right)(n-\mathrm{BuOH})_{0.5}\right)_{2}\left(\mathbf{c}-\mathrm{L}^{\mathbf{2 1}}\right)_{3}\right] \cdot 5 \mathrm{DMF}\right.$. $\left.\left.4(n-\mathrm{BuOH}) \cdot 2 \mathrm{H}_{2} \mathrm{O}\right)\right\}_{n}$ (30). The two compounds behaved as SMMs with an Orbach regime characterised by $\Delta=23.8 \mathrm{~K}, \tau_{0}=$ $2.39 \times 10^{-7} \mathrm{~s}$ for 29 and $\Delta=22.0 \mathrm{~K}, \tau_{0}=2.11 \times 10^{-7} \mathrm{~s}$ for 30 (Table 1). The authors could demonstrate through absorption spectroscopy that the two compounds presented a photochromic activity of the $\mathbf{o}-\mathbf{L}^{\mathbf{2 1}}$ or $\mathbf{c}-\mathbf{L}^{\mathbf{2 1}}$ ligands under light irradiation. After irradiation, the ac magnetic behaviour of 29 did not change while 30 showed a shift of the $\chi^{\prime \prime}{ }_{M}$ signal at higher frequencies. The modulation of the magnetic behaviour was attributed to the change in intermolecular interactions when the photochromic ligand is switched from one to the other form but unfortunately no X-ray structures of the systems after irradiation could be obtained.

Three years later, M. Yamashita and collaborators used the same ligand $\mathbf{o}-\mathbf{L}^{\mathbf{2 1}}$ to design a pure $4 \mathrm{f}$ system involving the most employed Dy(III) ion. A 2D-coordination network in which dinuclear Dy2-nodes are connected by a double $\mathbf{0}-\mathbf{L}^{21}$ bridge in one direction and simple $\mathbf{o}-\mathrm{L}^{\mathbf{2 1}}$ bridge in the other direction was reported. ${ }^{89}$ The $2 \mathrm{D}$ polymer $\left\{\left[\mathrm{Dy}_{2}\left(\mathbf{L}^{2 \mathbf{1 1}}\right)_{3}(\mathrm{DMSO})_{3}(\mathrm{MeOH})\right] \cdot 10 \mathrm{MeOH}\right\}_{n}(\mathbf{3 1})$ was exposed to UV irradiation $(350 \mathrm{~nm})$ and absorption spectroscopy undoubtedly showed the cyclisation of $\mathbf{L}^{21}$, nevertheless the diffraction pattern highlighted the loss of crystallinity. The cyclisation of $\mathbf{L}^{\mathbf{2 1}}$ is reversible since the open form can be recovered by visible irradiation $(480 \mathrm{~nm})$ but powder X-ray diffraction clearly demonstrated that the structural transformation due to UV irradiation was not reversible. In a magnetic point of view, 31 behaved as a field-induced SMM $(H=1500$ Oe $)$ with a thermally dependent regime at high temperature characterized by $\Delta=14.2 \mathrm{~K}$ and $\tau_{0}=1.90 \times 10^{-8} \mathrm{~s}$ and a remaining QTM at low temperature. After UV irradiation, the Orbach regime remained almost unchanged with $\Delta=14.7 \mathrm{~K}$ and $\tau_{0}=$ $7.25 \times 10^{-9} \mathrm{~s}$ while the QTM regime was affected since the system relaxed four times faster than before the irradiation. The authors attributed the changes of the QTM regime to geometrical variations in the Dy(III) surroundings after cyclisation of 31. After visible irradiation, the modulation of the magnetic behaviour was not significant. In other words, the closing and opening of $\mathbf{L}^{\mathbf{2 1}}$ were reversible while the structural and so the magnetic modulations were not.

In 2015, the same group continued its investigation of photochromic SMMs based on the $\mathbf{L}^{21}$ ligand introducing the 2,2'-bipyridine (bpy) blocking ligand to induce a better crystal field around the Dy(III) centre. Once again a 2D coordination polymer was obtained with the formula $\left[\mathrm{Dy}_{2}\left(\mathbf{L}^{\mathbf{2 1}}\right)_{3}(\mathrm{bpy})_{2}\left(\mathrm{H}_{2} \mathrm{O}\right)_{2}\right]_{n}(\mathbf{3 2}) \cdot{ }^{90}$ The Dy(III) ions lied in a $\mathrm{N}_{2} \mathrm{O}_{6}$ square anti-prism coordination sphere ( $D_{4 \mathrm{~d}}$ symmetry). 32 behaved as a SMM without applied magnetic field showing the effect of the introduction of the bpy ligand in the coordination sphere of the Dy(III) ion $\left(\Delta=14.5 \mathrm{~K}, \tau_{0}=5.33 \times 10^{-6} \mathrm{~s}\right.$ and $\tau_{\mathrm{QTM}}=2.77 \times 10^{-4} \mathrm{~s}$ ) (Table 1$)$. The QTM could be partially suppressed applying a field of 1000 Oe $\left(\Delta=21.7 \mathrm{~K}, \tau_{0}=8.1 \times 10^{-7} \mathrm{~s}\right.$ and $\tau_{\text {QTM }}=9.6 \times 10^{-3} \mathrm{~s}$ ). Absorption spectroscopy demonstrated that UV irradiation of $\mathbf{3 2}$ led to the cyclisation of $\mathbf{L}^{\mathbf{2 1}}$ while visible irradiation led to its opening. Unfortunately this technique also showed the irreversibility of the structural changes because the $\pi-\pi^{*}$ of the bpy and intra-ligand transition for $\mathbf{L}^{\mathbf{2 1}}$ were altered after visible irradiation compared to the starting 32 compound. After UV irradiation, the system still showed an out-of-phase signal of the magnetization but relaxed faster than before the irradiation and thus no maxima were observed. Under an applied field of 1000 Oe, the dynamic parameters could be extracted showing that the Orbach regime is only slightly modified while at low temperature the UVirradiated sample relaxed faster than the starting sample.

Finally, the carboxylate groups of $\mathbf{L}^{\mathbf{2 1}}$ were replaced by two 2,2'-bipyridine groups giving the new DTE derivative 1,2-bis(5-(2,2'-bipyridine)-2-methylthiophen-3-yl)cyclopent-1-ene $\left(\mathbf{L}^{22}\right) \cdot{ }^{91}$ The open form of this ligand $\left(\mathbf{o}-\mathbf{L}^{22}\right)$ was reacted with two equivalents of Dy(hfac) $)_{3} \cdot 2 \mathrm{H}_{2} \mathrm{O}$ leading to the formation of a dinuclear complex of formula $\left[\left(\text { Dy }(\text { hfac })_{3}\right)_{2}\left(\mathbf{o}-\mathbf{L}^{22}\right)\right](\mathbf{o}-33)$ (Fig. 12). The close form of the dinuclear complex was obtained after irradiation $(385 \mathrm{~nm})$ of the open form of the free ligand to give $\mathbf{c}-\mathbf{L}^{22}$ that was reacted with two equivalents of Dy $(\mathrm{hfac})_{3} \cdot 2 \mathrm{H}_{2} \mathrm{O}$ leading to $\mathbf{c}-33$. Since the cyclo-isomerisation is only active in solution, the conversion from o-33 to c-33 was not possible through single-crystal-to-single-crystal transformation.

Both open and close forms displayed field-induced SMMs $(H=1000 \mathrm{Oe})$ as often observed in the case of the association between bipyridine derivatives or similar nitrogenated bischelating ligands and Dy $(\beta \text {-diketonate })_{3}$ unit. $^{92} \mathrm{~A}$ combination of direct-Raman and direct-Orbach relaxation processes was determined for $\mathbf{0}-\mathbf{3 3}$ and $\mathbf{c - 3 3}$, respectively. In the bulk state, 

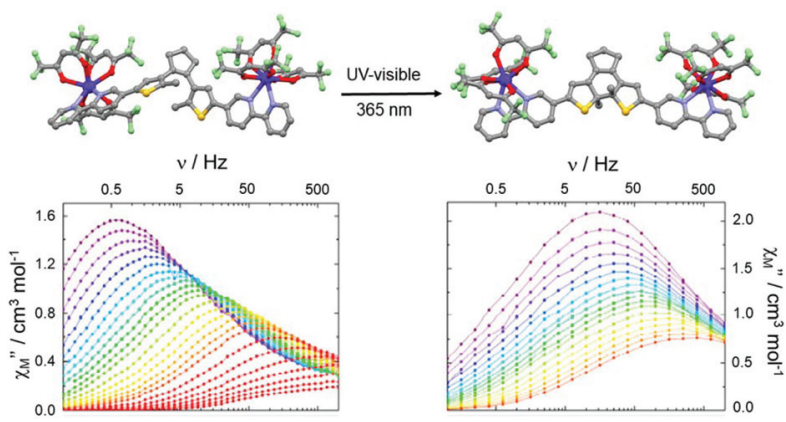

Fig. 12 Molecular structures and out-of-phase component of magnetic susceptibility for $0-33$ (left) and c-33 (right) for the temperature range from $1.85 \mathrm{~K}$ to $10 \mathrm{~K}$. Adapted from ref. 91.

c-33 highlighted a slower magnetic relaxation than o-33 but the different coordination symmetries $\left(D_{2 \mathrm{~d}}\right.$ for $\mathbf{0 - 3 3}$ and $D_{4 \mathrm{~d}}$ for c-33) associated with the distinct crystal packing made the interpretation difficult. Thus the authors studied the dynamic magnetic properties of the two forms in frozen solution leading to an almost similar magnetic behaviour. In other words, the cyclo-isomerization of the photochromic ligand $\mathbf{L}^{\mathbf{2 2}}$ induced only very small structural changes and thus the magnetic modulation remains weak at the molecular scale.

\subsection{1,2-Bis(4-pyridyl)ethene (bpe) photo-reactive ligand}

Other photoactive ligands can induce structural changes after irradiation. This is the case of the 1,2-bis(4-pyridyl)ethane ligand $\left(\mathbf{L}^{23}\right)$ which is well-known to realize photochemical $[2+2]$ cycloaddition with the formation of a cyclobutyl ring. ${ }^{93}$ Such photo-reaction was involved in the modulation of various physical properties but to the best of our knowledge only one article was devoted to SMM behaviour. ${ }^{94}$ The $\left[\operatorname{Dy}\left(\mathbf{L}^{23}\right)\right.$ $\left.\left(\mathrm{H}_{2} \mathrm{O}\right)_{4}\left(\mathrm{NO}_{3}\right)_{2}\right]\left(\mathrm{NO}_{3}\right) \cdot 2 \mathbf{L}^{23}(\mathbf{3 4})$ compound can be converted into $\left[\mathrm{Dy}_{2}\left(\mathbf{L}^{24}\right)\left(\mathrm{H}_{2} \mathrm{O}\right)_{8}\left(\mathrm{NO}_{3}\right)_{4}\right]\left(\mathrm{NO}_{3}\right)_{2} \cdot 2 \mathbf{L}^{23} \cdot \mathbf{L}^{\mathbf{2 4}}$ (35) (where $\mathbf{L}^{\mathbf{2 4}}=$ tetrakis (4-pyridyl)cyclobutane) by UV irradiation by a single-crystal-tosingle-crystal transformation (Fig. 13). AC magnetic investigation concluded a SMM behaviour for 34 but with $\chi^{\prime \prime}{ }_{M}$ maxima out from the experimental frequency window while 35 is not an SMM. The authors performed magnetic dilution to reduce the dipolar interactions, source of the efficiency of the QTM in these systems. 34@Y (dilution of 5.5\% of 34 in a Y(III) matrix) showed clear SMM behaviour with an Orbach regime at high temperature $\left(\Delta=55.1 \mathrm{~K}, \tau_{0}=9.81 \times 10^{-9} \mathrm{~s}\right)$. To better cancel the QTM, a magnetic field of 300 Oe was applied leading, as expected, to a shift of $\chi^{\prime \prime}{ }_{\mathrm{M}}$ signals to a lower frequency range than those obtained in the zero magnetic field. Similar magnetic measurements were done for 35@Y (dilution of $11 \%$ of 35 in a Y(III) matrix). SMM behaviour was detected only under an applied magnetic field with the following dynamic magnetic parameters for the Orbach regime $(\Delta=$ $47.9 \mathrm{~K}, \tau_{0}=1.22 \times 10^{-9} \mathrm{~s}$ ) (Table 1$)$.

The deviation from the linearity of the Arrhenius law could be fitted taking into account the remaining QTM, direct and Raman processes. At this point, it is clear that the photo$[2+2]$ cycloaddition induced a modulation of the magnetic

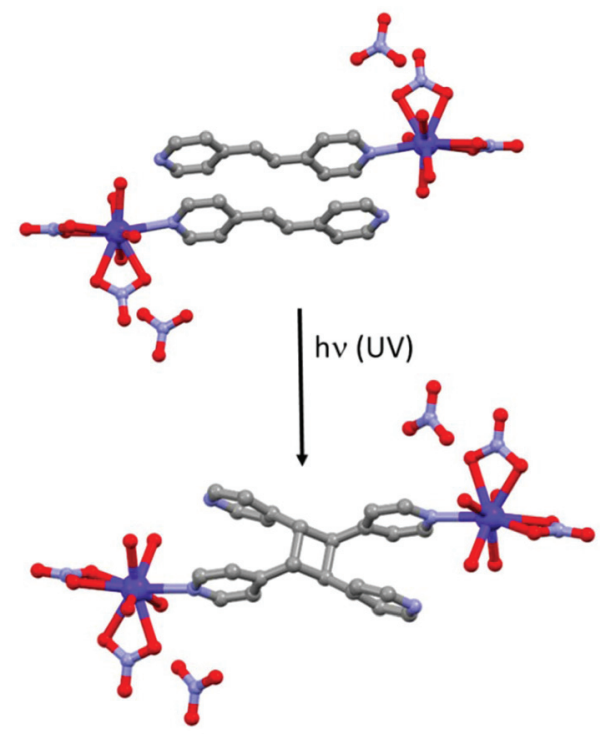

Fig. 13 Photochemical [2 + 2] cycloaddition occurring in 34 (top) leading to the formation of 35 (bottom).

properties from SMM behaviour for 34@Y to field-induced SMM for 35@Y. These observations were rationalized by $a b$ initio calculations which concluded (i) an higher Ising character $\left(g_{z}=19.09 v s . g_{z}=18.40\right)$, (ii) a greater energy gap between the ground state and the first excited state $(112.8 \mathrm{~K} v$ s. $72.7 \mathrm{~K})^{95}$ and (iii) less efficient QTM for 34@Y than for 35@Y.

\subsection{Spiropyran-merocyanine based-photochromic ligands}

Spiropyrans (SPs) are one of the best choices in the library of photochromic ligands. ${ }^{96}$ This class of ligands is very popular because of the cyclo-isomerization reaction to their merocyanine forms (trans-MC) upon light irradiation. ${ }^{97}$ Such reaction induces drastic structural and electronic modulations which have been exploited in several applications. ${ }^{98}$ The photochemical isomerization process is well-documented and it was clearly shown that the conversion of the trans-MC to SP form passes through a cis-conformation of the MC. ${ }^{99}$ Recently L. Norel and collaborators used the isomerization reaction from trans-MC to cis-MC to modulate the magnetic properties of a SMM. ${ }^{100}$ Thus a bis(pyridinemethyl)amine substituted spiropyran ligand ${ }^{101}$ was reacted with Dy(hfac $)_{3} \cdot 2 \mathrm{H}_{2} \mathrm{O}$ inducing the conversion of the spiropyran form into the trans-merocyanine form (trans- $\mathbf{L}^{\mathbf{2 5}}$ ) of the ligand and the formation of the mononuclear complex of formula $\left[\mathrm{Dy}\left(\right.\right.$ trans $\left.\left.-\mathrm{L}^{25}\right)(\mathrm{OTf})_{2}\left(\mathrm{H}_{2} \mathrm{O}\right)_{2}\right]$ OTf (trans-36). Trans-36 behaved as an SMM in both solid and frozen solution states with a similar Orbach regime at high temperature $(T>5 \mathrm{~K})\left(\Delta=32.9 \mathrm{~K}, \tau_{0}=1.24 \times 10^{-5} \mathrm{~s}\right.$ for solid state and $\Delta=35.4 \mathrm{~K}, \tau_{0}=4.51 \times 10^{-6} \mathrm{~s}$ for frozen solution state) (Table 1) while other under-barrier mechanisms are involved at low temperature $(T<5 \mathrm{~K})\left(\tau_{\mathrm{QTM}}=0.10 \mathrm{~s}\right.$ for solidstate and $0.14 \mathrm{~s}$ for frozen solution state). $A b$ initio calculations corroborate the Ising character of magnetic anisotropy $\left(g_{z}=\right.$ 19.69) as well as the presence of temperature-independent relaxation processes since the calculated energy difference 
between the ground state and the first excited state is overestimated (198.6 K). Under blue irradiation (450 nm) trans-36 was converted at $78 \%$ into the cis-36 form in solution. The ac magnetic measurements of cis-36 showed an almost unchanged Orbach regime $\left(\Delta=32.9 \mathrm{~K}, \tau_{0}=5.76 \times 10^{-7} \mathrm{~s}\right)$ compared to trans-36 while the low temperature regime was two times faster after irradiation $\left(\tau_{\mathrm{QTM}}=0.023 \mathrm{~s}\right)$. In other words, the trans-cis isomerization of $\mathbf{3 6}$ under irradiation induced slight magnetic modulation in frozen solution. Since the comparison of the magnetic behaviour was done in solution, the crystal packing effect should be neglected, and this might explain why the magnetic modulation is small. Similar observations were done for magnetic modulations of a DTE-based system after irradiation in solution (see section 5.1 with compounds o-33 and c-33). ${ }^{91}$

\subsection{Solvato-switching of single-molecule magnet in a photo-reactive system}

The last example of this section is one of the unique multiswitching of SMM behaviour with simultaneous photo- and solvato-switching phenomena. The concerned system was designed by reacting $\mathbf{L}^{26}$ (where $\mathbf{L}^{26}=N^{\prime}, N^{\prime \prime}, E, N^{\prime}, N^{\prime \prime}, E-N^{\prime}, N^{\prime \prime}$ (ethane-1,2-diylidene)dipyrazine-2-carbohydrazide), $\mathbf{L}^{27}$ (where $\mathbf{L}^{27}=9$-anthrylmethylphosphonic acid), sodium oxalate and $\mathrm{Dy}(\mathrm{OAc})_{3} \cdot 4 \mathrm{H}_{2} \mathrm{O}$. The resulting complex of formula $\left\{\left[\mathrm{Dy}_{5}\left(\mathbf{L}^{\mathbf{2 6}}\right)_{2}\left(\mu_{3}\right.\right.\right.$ $\left.\left.\mathrm{OAc})_{2}\left(\mu_{5}-\mathbf{L}^{27}\right)\left(\mu_{4}-\mathbf{L}^{27}\right)(\mu-\mathrm{OAc})_{2}(\mathrm{OAc})_{2}\left(\mathrm{H}_{2} \mathrm{O}\right)\left(\mathrm{CH}_{3} \mathrm{OH}\right)_{2}\right]_{2}\left(\mu_{4}-\mathrm{C}_{2} \mathrm{O}_{4}\right)\right\}$ (37) can be described as two cyclic pentanuclear complexes of Dy(III) linked by a $\mu_{4}$-oxalate ligand. ${ }^{102} 37$ did not behave as an SMM. After UV irradiation (365 nm) for 3 days, a single-crystalto-single-crystal transformation led to the system 37-UV which displayed slow magnetic relaxation. The temperature dependence of the relaxation time was fitted using eqn (1). ${ }^{103}$ Three regimes were characterized i.e. the Orbach regime at high temperature $\left(\Delta=47.3 \mathrm{~K}, \tau_{0}=1.26 \times 10^{-7} \mathrm{~s}\right)$ (Table 1$)$, a Raman process at intermediate temperature $\left(C=0.0011 \mathrm{~s}^{-1} \mathrm{~K}^{-n}\right.$ with $n=5.21$ ) and a combination of Raman/direct processes at low temperature $\left(A^{\prime}=3.58 \mathrm{~s}^{-1} \mathrm{~K}^{-1}\right.$ with $A^{\prime}=A H^{m}$ of eqn (1) and $\left.\tau_{\mathrm{QTM}}{ }^{-1}=0.0036 \mathrm{~s}^{-1}\right) .{ }^{104}$ The switch ON of the SMM behaviour after irradiation was associated with the change of the coordination mode for $\mathbf{L}^{27}$ from $\mu_{4}$ to $\mu_{5}$ and the replacement of two methanol molecules with two water molecules giving the formula $\left\{\left[\mathrm{Dy}_{5}\left(\mathbf{L}^{26}\right)_{2}\left(\mu_{3}-\mathrm{OAc}\right)_{2}\left(\mu_{5}-\mathbf{L}^{27}\right)_{2}(\mu-\mathrm{OAc})_{2}(\mathrm{OAc})_{2}\left(\mathrm{H}_{2} \mathrm{O}\right)_{3}\right]_{2}\left(\mu_{4}-\mathrm{C}_{2} \mathrm{O}_{4}\right)\right\}$ for 37-UV. Consequently the crystal field around the Dy(II) ions was modified as attested by $a b$ initio calculations showing the increase of both the energy gap between the ground state and the first excited state from $102.4 \mathrm{~K}$ to $128.9 \mathrm{~K}$ and the axial character of the magnetic anisotropy from $g_{z}=18.51$ to $g_{z}=19.41$. Even more remarkable is that 37-UV could evolve to $37-\mathrm{Ar} / \mathrm{N} 2$ by a second single-crystal-to-single-crystal transformation by heating at $100{ }^{\circ} \mathrm{C}$ under an argon (37-Ar) or nitrogen (37-N2) atmosphere. This second transformation led to the switch OFF of the SMM behaviour due to the loss of two (37-N2) or three (37-Ar) coordinated water molecules. Nevertheless it was difficult to rationalize the magnetic behaviour after annealing with $a b$ initio calculations because the average energy gap and Ising character for 37-Ar are close to those of 37-UV with $\Delta=126.5 \mathrm{~K}$ and $g_{z}=19.33$.
In addition, significant intramolecular interactions were calculated $(J=-0.76 \mathrm{~K}$ for $37, J=-1.29 \mathrm{~K}$ for $37-\mathrm{UV}$ and $J=0.46 \mathrm{~K}$ for 37-Ar) without the determination of their respective role in the observation or not of slow magnetic relaxation.

\section{Proton switching of single- molecule magnet behaviour}

The previous section of this review showed that the dibenzotetraaza[14]annulenes like phthalocyanines or porphyrins are suitable macrocyclic ligands to design redox-active SMMs (see section 2.2), to observe redox-switching (see section 3.1) and solvato-switching (see section 4) SMM behaviour. The last section of the review shows that such ligands are also suitable for proton switching of the SMM behaviour.

A recent example of such switching has been published by M. Yamashita and collaborators for a mononuclear doubledecker complex made from a Dy(III) centre and an indolenine meso-substituted dibenzotetraaza[14]-annulene ligand $\left(\mathbf{L}^{\mathbf{2 8}}\right) .{ }^{105}$ In the absence of a base and acid in the reaction mixture the compound of formula $\mathrm{H}\left[\mathrm{Dy}\left(\mathbf{L}^{28}\right)_{2}\right]$-solvents (H-38) was obtained. Both ${ }^{1} \mathrm{H}-\mathrm{NMR}$ and DFT methods concluded the position of the proton on the indolenine $\mathrm{N}$-atom rather than on a $\mathrm{N}$-atom of the annulene moiety. In the presence of an excess of acetic acid $\mathbf{H}-\mathbf{3 8}$ could be protonated to give $\mathbf{H}_{2}-\mathbf{3 8}$ whereas with an excess of 1,8-diazabicyclo[5.4.0]-undec-7-ene base (DBU) H-38 could be deprotonated leading to 38 . The three compounds have been magnetically studied in frozen solution and under an applied magnetic field of 1000 Oe. The neutral H-38 compound behaved as a field-induced SMM and its magnetization relaxed through both direct $\left(A=9.88 \times 10^{-13} \mathrm{~s}^{-1}\right.$ $\mathrm{Oe}^{-4} \mathrm{~K}^{-2}$ with direct process expressed as $\left.A T^{2} H^{4}\right)$ and Raman $\left(C=8.27 \times 10^{-4} \mathrm{~s}^{-1} \mathrm{~K}^{-n}\right.$ with $n=9$ ) processes (see eqn (1)).

After protonation of $\mathbf{H}-\mathbf{3 8}$, the magnetization of the cationic $\mathbf{H}_{2}$-38 compound relaxed faster through a complex association of mechanisms i.e. Orbach $\left(\Delta=70.6 \mathrm{~K}, \tau_{0}=1.40 \times 10^{-12} \mathrm{~s}\right)$, direct $\left(A=7.74 \times 10^{-12} \mathrm{~s}^{-1} \mathrm{Oe}^{-4} \mathrm{~K}^{-2}\right)$ and Raman $(C=5.48 \times$ $10^{-2} \mathrm{~s}^{-1} \mathrm{~K}^{-n}$ with $n=9$ ) processes. In contrast, after deprotonation of $\mathbf{H - 3 8}$, the magnetization of the anionic 38 compound relaxed slower through an Orbach regime $\left(\Delta=56.1 \mathrm{~K}, \tau_{0}=\right.$ $\left.1.25 \times 10^{-8} \mathrm{~s}\right)$ and a Raman contribution $\left(C=3.33 \times 10^{-4} \mathrm{~s}^{-1} \mathrm{~K}^{-n}\right.$ with $n=9$ ). The relaxation of magnetization for 38 was slow enough to observe a SMM behaviour in zero applied magnetic field for which an Orbach regime $\left(\Delta=34.7 \mathrm{~K}, \tau_{0}=2.51 \times 10^{-7}\right.$ s) and QTM $\left(\tau_{\mathrm{QTM}}=2.7 \times 10^{-3} \mathrm{~s}\right)$ were identified. In conclusion the following trend for magnetic modulation was observed $\tau\left(\mathbf{H}_{2}-\mathbf{3 8}\right)<\tau(\mathbf{H}-\mathbf{3 8})<\tau(\mathbf{3 8})$ and it might be attributed to the increase of the under-barrier relaxation process contributions (direct and Raman) when protonation of the sample occurred. The second example of protonation/deprotonation of the first coordination sphere of the lanthanide is another doubledecker complex made from the tetraphenylporphyrin $\left(\mathbf{L}^{\mathbf{2 9}}\right)$ macrocycle and $\mathrm{Tb}(\mathrm{III})$ ion. ${ }^{106}$ The protonated form has the formula $\left[\mathrm{TbH}\left(\mathbf{L}^{29}\right)_{2}\right]$ (39) while the deprotonated form has the formula $\left[\mathrm{Tb}\left(\mathbf{L}^{29}\right)_{2}\right](\mathrm{H}-\mathrm{DBU})$ (40) (Fig. 14). The reversibility of 


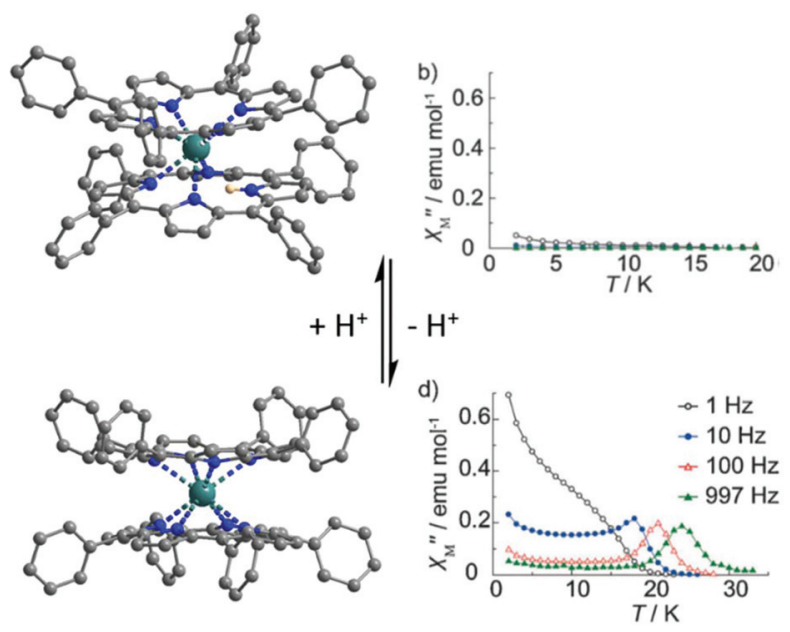

Fig. 14 Crystal structure of 39 (top) and $\mathbf{4 0}$ (bottom) with their associated out-of-phase magnetic susceptibility contributions. Colour code: terbium: turquoise and hydrogen: light pink. Adapted from ref. 106.

the protonation/deprotonation process was verified by absorption spectroscopy. The presence of the protonated $\mathbf{L}^{29}$ was attested by electrochemistry with only four single-electron oxidation waves for $\mathbf{4 0}$ while six peaks were observed for 39. The two additional oxidation peaks in $\mathbf{3 9}$ were previously attributed to the protonated double-decker complex. ${ }^{107}$ The X-ray structures revealed a significant difference. Thus the $\mathrm{Tb}$ (III) centre is seven coordinated in $\mathbf{3 9}$ while it is eight coordinated in $\mathbf{4 0}$. The twisted angle value increases from $35^{\circ}$ in 39 to $45^{\circ}$ in 40 . These structural modifications led to drastic changes in the magnetic properties since the SMM behaviour is switched on after deprotonation with an Orbach relaxation process in zero $\left(\Delta=387.1 \mathrm{~K}, \tau_{0}=1.6 \times 10^{-11} \mathrm{~s}\right)$ (Table 1 ) or applied magnetic field (2000 Oe) $\left(\Delta=407.2 \mathrm{~K}, \tau_{0}=6.8 \times 10^{-12} \mathrm{~s}\right)$ (Fig. 14). The proton switching of the SMM behaviour was associated with the loss of Ising-type magnetic anisotropy after protonation (seven-coordination instead of $D_{4 \mathrm{~d}}$ eight-coordination) leading to a large off-diagonal ligand field symmetry and thus a loss of SMM behaviour. ${ }^{23 a}$ One more time, one could remark that the deprotonation led to an enhancement of the magnetic properties with much more drastic effect since the protonation/ deprotonation process took place on the first coordination sphere of the lanthanide ion.

\section{Conclusions and perspectives}

The electro-activity and magnetic-switching of lanthanide SMMs are recent phenomena making such research fields grow quickly in less than 10 years. This article reviewed the main stimuli which can be used to modulate the SMM behaviour i.e. oxidation/reduction, solvation/desolvation and protonation/deprotonation processes, and light irradiation. Starting from the quite large pool of redox active lanthanide SMMs, the redox-switching of SMM behaviour is the most developed phenomena. It can be centred on the organic ligand or the metal ion. It is also probably the most complicated phenomena to understand because oxidation/reduction processes induced both change in the spin state and structural modifications. Thus magnetic interaction and electronic distribution could be simultaneously altered and need to be well understood to give a clear interpretation of the magnetic switching. For the solvato-, photo- and proton-switching of the SMM behaviour, the crucial parameter is the modification of the structural properties under the applied stimulus. The degree of change of the symmetry, electronic distribution around the lanthanide and crystal packing drives the importance of magnetic modulations. In this context, the phenomena of solvation/desolvation and protonation/deprotonation which took place in the first coordination sphere of the lanthanide ion have remarkable effects on the magnetic properties with ONOFF switching of the SMM behaviour (Table 1). In contrast, structural changes which took place far from the metal centre such as change of solvent matrix or cyclo-isomerisation of DTE derivatives under light irradiation have only a slight effect on the magnetic properties. In these cases, the change of crystal packing i.e. change of dipolar interactions, took precedence over molecular structural changes. Lanthanide ions for the design of molecular switches are amazing suitable candidates since they are the metal ions most sensitive to any slight changes of structural properties especially compared to transition metal ions for which the switch of physical properties under external stimuli is mainly due to the change of their electronic configuration (metal-centred oxidation, change of spin-state etc. $\cdots) .{ }^{13-16}$ Thus examples of lanthanide molecular switches will expand undoubtedly in the near future.

\section{Conflicts of interest}

There are no conflicts to declare.

\section{Acknowledgements}

This work was supported by the Universite de Rennes 1, CNRS France-Russia MULTISWITCH PRC grant (no. 199001) and the European Commission through the ERC-CoG 725184 MULTIPROSMM (project no. 725184).

\section{Notes and references}

1 R. Sessoli, H. L. Tsai, A. R. Schake, S. Y. Wang, J. B. Vincent, K. Folting, D. Gatteschi, G. Christou and D. N. Hendrickson, J. Am. Chem. Soc., 1993, 115, 18041816.

2 D. Gatteschi, R. Sessoli and J. Villain, Molecular Nanomagnets, Oxford Univ. Press, 2006.

3 M. Mannini, F. Pineider, P. Sainctavit, C. Danieli, E. Otero, C. Sciancalepore, A. M. Talarico, M.-A. Arrio, 
A. Cornia, D. Gatteschi and R. Sessoli, Nat. Mater., 2009, 8, 194-197.

4 S. Thiele, F. Balestro, R. Ballou, S. Klyatskaya, M. Ruben and W. Wernsdorfer, Science, 2014, 344, 1135-1138.

5 K. S. Pedersen, A.-M. Ariciu, S. McAdams, H. Weihe, J. Bendix, F. Tuna and S. Piligkos, J. Am. Chem. Soc., 2016, 138, 5801-5804.

6 (a) F.-S. Guo, B.-M. Day, Y.-C. Chen, M.-L. Tong, A. Mansikkamäki and R. A. Layfield, Angew. Chem., Int. Ed., 2017, 56, 11445-11449; (b) C. A. P. Goodwin, F. Ortu, D. Reta, N. F. Chilton and D. P. Mills, Nature, 2017, 548, 439-442; (c) K. R. McClain, C. A. Gould, K. Chakarawet, S. J. Teat, T. J. Groshens, J. R. Long and B. G. Harvey, Chem. Sci., 2018, 9, 8492-8503; (d) F.-S. Guo, B.-M. Day, Y.-C. Chen, M.-L. Tong, A. Mansikkamäki and R. A. Layfield, Science, 2018, 362, 1400-1403.

7 (a) J. M. Zadrozny, M. Atanasov, A. M. Bryan, C.-Y. Lin, B. D. Rekken, P. P. Power, F. Neese and J. R. Long, Chem. Sci., 2013, 4, 125-138; (b) R. L. Carlin, Magnetochemistry, Springer, Berlin, 1986.

8 (a) A. Singh and K. N. Shrivastava, Phys. Status Solidi B, 1979, 95, 273-277; (b) K. N. Shirivastava, Phys. Status Solidi B, 1983, 177, 437-458.

9 T. Fukuda, K. Matsumura and N. Ishikawa, J. Phys. Chem. A, 2013, 117, 10447-10454.

10 (a) F. Pointillart, Y. Le Gal, S. Golhen, O. Cador and L. Ouahab, Chem. - Eur. J., 2011, 17, 10397-10404; (b) X. Yi, K. Bernot, O. Cador, J. Luzon, G. Calvez, C. Daiguebonne and O. Guillou, Dalton Trans., 2013, 42, 6728-6731; (c) F.-S. Guo and R. A. Layfield, Chem. Commun., 2017, 53, 3130-3133; (d) H. Tian, B.-L. Wang, J. Lu, H.-T. Liu, J. Su, D. Li and J. Dou, Chem. Commun., 2018， 54，12105-12108; (e) L. Zhang, Y.-Q. Zhang, P. Zhang, L. Zhao, M. Guo and J. Tang, Inorg. Chem., 2017, 56, 7882-7889; $(f)$ M. J. Giansiracusa, E. Moreno-Pineda, R. Hussain, R. Marx, M. Martinez Prada, P. Neugebauer, S. Al-Badran, D. Collison, F. Tuna, J. van Slageren, S. Carretta, T. Guidi, E. J. L. McInnes, R. E. P. Winpenny and N. F. Chilton, J. Am. Chem. Soc., 2018, 140, 25042513.

11 (a) F. Luis, M. J. Martinez-Pérez, O. Montero, E. Coronado, S. Cardona-Serra, C. Marti-Gastaldo, J.-M. Clemente-Juan, J. Sesé, D. Drung and T. Schurig, Phys. Rev. B: Condens. Matter Mater. Phys., 2010, 82, 060403; (b) F. Pointillart, K. Bernot, S. Golhen, B. Le Guennic, T. Guizouarn, L. Ouahab and O. Cador, Angew. Chem., Int. Ed., 2015, 54, 1504-1507; (c) Y. Kishi, F. Pointillart, B. Lefeuvre, F. Riobé, B. Le Guennic, S. Golhen, O. Cador, O. Maury, H. Fujiwara and L. Ouahab, Chem. Commun., 2017, 53, 3575-3578; (d) E. Moreno-Pineda, M. Damjanovic, O. Fuhr, W. Wernsdorfer and M. Ruben, Angew. Chem., Int. Ed., 2017, 56, 9915-9919; (e) Y.-C. Chen, J.-L. Liu, W. Wernsdorfer, D. Liu, L. F. Chibotaru, X.-M. Chen and M.-L. Tong, Angew. Chem., Int. Ed., 2017, 56, 4996-5000; (f) J. Flores Gonzalez, F. Pointillart and O. Cador, Inorg.
Chem. Front., 2019, 6, 1081-1086; O. Sato, Nat. Chem., 2016, 8, 644-656.

12 (a) O. Sato, Nat. Chem., 2016, 8, 644-656; (b) W.-B. Chen, Y.-C. Chen, J.-L. Liu, J.-H. Jia, L.-F. Wang, Q.-W. Li and M.-L. Tong, Inorg. Chem., 2017, 56, 8730-8734.

13 (a) M. Mannini, F. Pineider, C. Danieli, F. Totti, L. Sorace, P. Sainctavit, M.-A. Arrio, E. Otero, L. Joly, J. C. Cezar, A. Cornia and R. Sessoli, Nature, 2010, 468, 417-421; (b) R. Vincent, S. Klyatskaya, M. Ruben, W. Wernsdorfer and F. Balestro, Nature, 2012, 488, 357-359; (c) A. Coskun, J. M. Spruell; G. Barin, W. R. Dichtel, A. H. Flood, Y. Y. Botros and J. F. Stoddart, Chem. Soc. Rev., 2012, 41, 4827-4859.

14 (a) X. Feng, C. Mathonière, I.-R. Jeon, M. Rouzières, A. Ozarowski, M. L. Aubrey, M. I. Gonzalez, R. Clérac and J. R. Long, J. Am. Chem. Soc., 2013, 135, 15880-15884; (b) C. Mathonière, H.-J. Lin, D. Siretanu, R. Clérac and J. M. Smith, J. Am. Chem. Soc., 2013, 135, 19083-19086.

15 S. Fortier, J. J. Le Roy, C.-H. Chen, V. Vieru, M. Murugesu, L. F. Chibotaru, D. J. Mindiola and K. G. Caulton, J. Am. Chem. Soc., 2013, 135, 14670-14678.

16 (a) G. N. Newton, S. Yamashita, K. Hasumi, J. Matsuno, N. Yoshida, M. Nihei, T. Shiga, M. Nakano, H. Nojiri, W. Wernsdorfer and H. Oshio, Angew. Chem., Int. Ed., 2011, 50, 5716-5720; (b) W. Jiang, C. Jiao, Y. Meng, L. Zhao, Q. Liu and T. Liu, Chem. Sci., 2018, 9, 617-622.

17 (a) J. Vallejo, E. Pardo, M. Viviano-Chumillas, I. Castro, P. Amoros, M. Deniz, C. Ruiz-Perez, C. Yuste-Vivas, J. Krzystek, M. Julve, F. Lloret and J. Cano, Chem. Sci., 2017, 8, 3694-3702; (b) D. Q. Wu, D. Shao, X.-Q. Wei, F.-X. Shen, L. Shi, D. Kempe, Y.-Z. Zhang, K. R. Dunbar and X.-Y. Wang, J. Am. Chem. Soc., 2017, 139, 1171411717; (c) D. Shao, L. Shi, L. Yin, B.-L. Wang, Z.-X. Wang, Y.-Q. Zhang and X.-Y. Wang, Chem. Sci., 2018, 9, 79867991.

18 (a) C. Carbonera, A. Dei, J.-F. Létard, C. Sangregorio and L. Sorace, Angew. Chem., Int. Ed., 2004, 43, 3136-3138; (b) J. Tao, H. Maruyama and O. Sato, J. Am. Chem. Soc., 2006, 128, 1790-1791.

19 A. Md Subhan, R. Kawahata, H. Nakata, A. Fuyuhiro, T. Tsukuda and S. Kaizaki, Inorg. Chim. Acta, 2004, 357, 3139-3146.

20 M. A. Dunstan, E. Rousset, M.-E. Boulon, R. W. Gable, L. Sorace and C. Boskovic, Dalton Trans., 2017, 46, 1375613767.

21 D. Guo and J. K. McCusker, Inorg. Chem., 2007, 46, 32573274.

22 N. Ishikawa, M. Sugita, T. Ishikawa, S.-Y. Koshihara and Y. Kaizu, J. Am. Chem. Soc., 2003, 125, 8694-8695.

23 (a) N. Ishikawa, M. Sugita and W. Wernsdorfer, Angew. Chem., Int. Ed., 2005, 44, 2931-2935; (b) N. Ishikawa, M. Sugita, T. Ishikawa, S.-Y. Koshihara and Y. Kaizu, J. Phys. Chem. B, 2004, 108, 11265-11271; (c) N. Ishikawa, M. Sugita and W. Wernsdorfer, J. Am. Chem. Soc., 2005, 127, 3650-3651; (d) N. Ishikawa, Polyhedron, 2007, 26, 2147-2153. 
24 H.-G. Jin, X. Jiang, I. A. Kühne, S. Clair, V. Monnier, C. Chendo, G. Novitchi, A. K. Powell, K. M. Kadish and T. S. Balaban, Inorg. Chem., 2017, 56, 4864-4873.

25 (a) P. Zhu, F. Lu, N. Pan, D. P. Arnold, S. Zhang and J. Jiang, Eur. J. Inorg. Chem., 2004, 510-517; (b) K. M. Kadish, T. Nakanishi, A. Gurek, V. Ahsen and I. Yilmaz, J. Phys. Chem. B, 2001, 105, 9817-9821.

26 L. Vitali, S. Fabris, A. M. Conte, S. Brink, M. Ruben, S. Baroni and K. Kern, Nano Lett., 2008, 8, 3364-3368.

27 M. Mannini, P. Sainctavit, R. Sessoli, C. Cartier dit Moulin, F. Pineider, M. A. Arrio, A. Cornia and D. Gatteschi, Chem. - Eur. J., 2008, 14, 7530-7535.

28 M. Gonidec, D. B. Amabilino and J. Veciana, Dalton Trans., 2012, 41, 13632-13639.

29 D. P. Arnold and J. Jiang, J. Phys. Chem. A, 2001, 105, 7525-7533.

30 M. Gonidec, F. Luis, À. Vílchez, J. Esquena, D. B. Amabilino and J. Veciana, Angew. Chem., Int. Ed., 2010, 49, 1623-1626.

31 M. Waters, F. Moro, I. Krivokapic, J. McMaster and J. V. Slageren, Dalton Trans., 2012, 41, 1128-1130.

32 (a) J. M. Williams, J. R. Ferraro, R. J. Thorn, K. D. Carlson, U. Geiser, H. H. Wang, A. M. Kini and M.-H. Whangbo, Organic Superconductors (Including Fullerenes), Synthesis, Structure, Properties and Theory, Prentice Hall, 1992; (b) M. R. Bryce, J. Mater. Chem., 1995, 5, 1469-1479; (c) J. L. Segura and N. Martin, Angew. Chem., Int. Ed., 2001, 40, 1372-1409; (d) P. Batail, Chem. Rev., 2004, 104, 48874890 (and the following articles of this thematic issue).

33 D. Lorcy, N. Bellec, M. Fourmigué and N. Avarvari, Coord. Chem. Rev., 2009, 253, 1398-1438.

34 (a) F. Pointillart, S. Golhen, O. Cador and L. Ouahab, Dalton Trans., 2013, 42, 1949-1960; (b) F. Pointillart, B. Le Guennic, O. Cador, O. Maury and L. Ouahab, Acc. Chem. Res., 2015, 48, 2834-2842.

35 J.-C. Wu, S.-X. Liu, T. D. Keene, A. Neels, V. Mereacre, A. K. Powell and S. Decurtins, Inorg. Chem., 2008, 47, 3452-3459.

36 (a) G. Cosquer, F. Pointillart, Y. Le Gal, S. Golhen, O. Cador and L. Ouahab, Chem. - Eur. J., 2011, 17, 1250212511; (b) G. Cosquer, F. Pointillart, B. Le Guennic, Y. Le Gal, S. Golhen, O. Cador and L. Ouahab, Inorg. Chem., 2012, 51, 8488-8501.

37 F. Gao, L. Cui, W. Liu, L. Hu, Y.-W. Zhong, Y.-Z. Li and J.-L. Zuo, Inorg. Chem., 2013, 52, 11164-11172.

38 F. Pointillart, Y. Le Gal, S. Golhen, O. Cador and L. Ouahab, Chem. - Eur. J., 2011, 17, 10397-10404.

39 F. Pointillart, B. Le Guennic, O. Maury, S. Golhen, O. Cador and L. Ouahab, Inorg. Chem., 2013, 52, 13981408.

40 (a) F. Habib, P.-H. Lin, J. Long, I. Korobkov, W. Wernsdorfer and M. Murugesu, J. Am. Chem. Soc., 2011, 133, 8830-8833; (b) X. Yi, K. Bernot, F. Pointillart, G. Poneti, G. Calvez, C. Daiguebonne, O. Guillou and R. Sessoli, Chem. - Eur. J., 2012, 18, 11379-11387; (c) C. Y. Chow, H. Bolvin, V. E. Campbell, R. Guillot,
J. W. Kampf, W. Wernsdorfer, F. Gendron, J. Autschbach, V. L. Pecoraro and T. Mallah, Chem. Sci., 2015, 6, 41484159; (d) S. Xue, Y.-N. Guo, L. Ungur, J. Tang and L. F. Chibotaru, Chem. - Eur. J., 2015, 21, 14099-14106.

41 (a) F. Pointillart, B. Le Guennic, S. Golhen, O. Cador, O. Maury and L. Ouahab, Chem. Commun., 2013, 49, 615617; (b) F. Pointillart, S. Golhen, O. Cador and L. Ouahab, Eur. J. Inorg. Chem., 2014, 4558-4563.

42 F. Pointillart, O. Cador, B. Le Guennic and L. Ouahab, Coord. Chem. Rev., 2017, 346, 150-175.

43 K. Soussi, J. Jung, F. Pointillart, B. Le Guennic, B. Lefeuvre, S. Golhen, O. Cador, Y. Guyot, O. Maury and L. Ouahab, Inorg. Chem. Front., 2015, 2, 1105-1117.

44 C. Jia, S.-X. Liu, C. Tanner, C. Leiggener, A. Neels, L. Sanguinet, E. Levillain, S. Leutwyler, A. Hauser and S. Decurtins, Chem. - Eur. J., 2007, 13, 3804-3812.

45 B. Chen, Z.-P. Lv, C. Hua, C. F. Leong, F. Tuna, D. M. D'Alessandro, D. Collison and J.-L. Zuo, Inorg. Chem., 2016, 55, 4606-4615.

46 V. Kuropatov, S. Klementieva, G. Fukin, A. Mitin, S. Ketkov, Y. Budnikova, V. Cherkasoc and G. Abakumov, Tetrahedron, 2010, 66, 7605-7611.

47 Y. Yamashita, Y. Kobayashi and T. Miyashi, Angew. Chem., Int. Ed. Engl., 1989, 28, 1052-1053.

48 N. O. Chalkov, V. K. Cherkasov, G. A. Abakumov, G. V. Romanenko, S. Y. Ketkov, I. V. Smolyaninov, A. G. Starikov and V. A. Kuropatov, Eur. J. Org. Chem., 2014, 4571-4576.

49 J. F. Gonzalez, O. Cador, L. Ouahab, S. Norkov, V. Kuropatov and F. Pointillart, Inorganics, 2018, 6, 45-54.

50 F. Gao, X.-M. Zhang, L. Cui, K. Deng, Q.-D. Zeng and J.-L. Zuo, Sci. Rep., 2014, 4, 5928-5935.

51 F. Pointillart, B. Le Guennic, S. Golhen, O. Cador and L. Ouahab, Chem. Commun., 2013, 49, 11632-11634.

52 J. S. Scout, Semiconductor and Semimetals, in Highly Conducting Quasi-One-Dimensional Organic Crystals, ed. E. Conswell, Academic Press, New York, 1988, vol. 27, p. 385.

53 C. Jia, S.-X. Liu, C. Tanner, C. Leiggener, A. Neels, L. Sanguinet, E. Levillain, S. Leutwyler, A. Hauser and S. Decurtins, Chem. - Eur. J., 2007, 13, 3804-3812.

54 (a) M. A. Dunstan, E. Rousset, M.-E. Boulon, R. W. Gable, L. Sorace and C. Boskovic, Dalton Trans., 2017, 46, 1375613767; (b) J. O. Moilanen, A. Mansikkamaki, M. Lahtinen, F.-S. Guo, E. Kalenius, R. A. Layfield and L. F. Chibotaru, Dalton Trans., 2017, 46, 13582-13589.

55 J. D. Rinehart, M. Fang, W. J. Evans and J. R. Long, Nat. Chem., 2011, 3, 538-542.

56 (a) J. D. Rinehart, M. Fang, W. J. Evans and J. R. Long, J. Am. Chem. Soc., 2011, 133, 14236-14239; (b) S. Demir, J. M. Zadrozny, M. Nippe and J. R. Long, J. Am. Chem. Soc., 2012, 134, 18546-18549; (c) S. Demir, M. Nippe, M. I. Gonzalez and J. R. Long, Chem. Sci., 2014, 5, 47014711; $\quad(d) \quad$ B. S. Dolinar, S. Gomez-Coca, D. I. Alexandropoulos and K. R. Dunbar, Chem. Commun., 2017, 53, 2283-2286; (e) C. A. Gould, L. E. Darago, M. I. Gonzalez, S. Demir and J. R. Long, Angew. Chem., Int. 
Ed., 2017, 56, 10103-10107; (f) F.-S. Guo and R. A. Layfeld, Chem. Commun., 2017, 53, 3130-3133.

57 P. Zhang, M. Perfetti, M. Kern, P. P. Hallmen, L. Ungur, S. Lenz, M. R. Ringenberg, W. Frey, H. Stoll, G. Rauhut and J. van Slageren, Chem. Sci., 2018, 9, 1221-1230.

58 B. S. Dolinar, S. Gomez-Coca, D. I. Alexandropoulos and K. R. Dunbar, Chem. Commun., 2017, 53, 2283-2286.

59 A. V. Ivanov, P. A. Zhukov, L. G. Tomilova and N. S. Zefirov, Russ. Chem. Bull., 2006, 55, 281-286.

60 S. Takamatsu, T. Isikawa, S.-Y. Koshihara and N. Ishikawa, Inorg. Chem., 2007, 46, 7250-7252.

61 M. Gonidec, E. S. Davies, J. McMaster, D. B. Amabinino and J. Veciana, J. Am. Chem. Soc., 2010, 132, 1756-1757.

62 (a) E. J. L. McInnes, E. Pidcock, V. S. Oganesyan, M. R. Cheesman, A. K. Powell and A. J. Thomson, J. Am. Chem. Soc., 2002, 124, 9219-9228; (b) N. Domingo, B. E. Williamson, J. Gomez-Segura, P. Gerbier, D. RuizMolina, D. B. Amabilino, J. Veciana and J. Tejada, Phys. Rev. B: Condens. Matter Mater. Phys., 2004, 69, 052405; (c) P. Gerbier, N. Domingo, J. Gomez-Segura, D. RuizMolina, D. B. Amabilino, J. Tejada, B. E. Williamson and J. Veciana, J. Mater. Chem., 2004, 14, 2455-2460; (d) M. R. Cheesman, V. S. Oganesyan, R. Sessoli, D. Gatteschi and A. J. Thomson, Chem. Commun., 1997, 1677-1678.

63 L. Norel, M. Feng, K. Bernot, T. Roisnel, T. Guizouarn, K. Costuas and S. Rigaut, Inorg. Chem., 2014, 53, 23612363.

64 F. Meng, Y.-M. Hervault, Q. Shao, B. Hu, L. Norel, S. Rigaut and X. Che, Nat. Commun., 2014, 5, 3023-3303.

65 K. A. Green, M. P. Cifuentes, M. Samoc and M. G. Humphrey, Coord. Chem. Rev., 2011, 255, 25302541.

66 E. Di Piazza, L. Norel, K. Costuas, A. Bourdolle, O. Maury and S. Rigaut, J. Am. Chem. Soc., 2011, 133, 6174-6176.

67 C. M. Dickie, A. L. Laughlin, J. D. Wofford, N. S. Bhuvanesh and M. Nippe, Chem. Sci., 2017, 8, 8039-8049.

68 (a) V. V. Novikov, A. A. Pavlov, Y. V. Nelyubina, M.-E. Boulon, O. A. Varzatskii, Y. Z. Voloshin and R. E. P. Winpenny, J. Am. Chem. Soc., 2015, 137, 97929795; (b) S. T. Liddle and J. van Slageren, Chem. Soc. Rev., 2015, 44, 6655-6669.

69 B. S. Brunschwig, C. Creutz and N. Sutin, Chem. Soc. Rev., 2002, 31, 168-184.

70 E. M. Broderick, N. Guo, C. S. Vogel, C. Xu, J. Sutter, J. T. Miller, K. Meyer, P. Mehrkhodavandi and P. L. Diaconescu, J. Am. Chem. Soc., 2011, 133, 9278-9281.

71 S. Patra, T. A. Miller, B. Sarkar, M. Niemeyer, M. D. Ward and G. K. Lahiri, Inorg. Chem., 2003, 42, 4707-4713.

72 K. Suzuki, R. Sato and N. Mizuno, Chem. Sci., 2013, 4, 596-600.

73 J.-L. Liu, Y.-C. Chen, Y.-Z. Zheng, W.-Q. Lin, L. Ungur, W. Wernsdorfer, L. F. Chibotaru and M.-L. Tong, Chem. Sci., 2013, 4, 3310-3316.

74 (a) J. D. Rinehart and J. R. Long, Chem. Sci., 2011, 2, 2078-2085; (b) L. Sorace, C. Benelli and D. Gatteschi,
Chem. Soc. Rev., 2011, 40, 3092-3104; (c) D. Gatteschi, Nat. Chem., 2011, 3, 830; (d) D. N. Woodruff, R. E. P. Winpenny and R. A. Layfield, Chem. Rev., 2013, 113, 5110-5148; (e) H. L. C. Feltham, Y. Lan, F. Klöwer, L. Ungur, L. F. Chibotaru, A. K. Powell and S. Brooker, Chem. - Eur. J., 2011, 17, 4362-4365; (f) A. Yamashita, A. Watanabe, S. Akine, T. Nabeshima, M. Nakano, T. Yamamura and T. Kajiwara, Angew. Chem., Int. Ed., 2011, 50, 4016-4019.

75 J.-L. Liu, K. Yuan, J.-D. Leng, L. Ungur, W. Wernsdorfer, F.-S. Guo, L. F. Chibotaru and M.-L. Tong, Inorg. Chem., 2012, 51, 8538-8544.

76 (a) A. Singh and K. N. Shrivastava, Phys. Status Solidi B, 1979, 95, 273-277; (b) K. N. Shrivastava, Phys. Status Solidi $B, 1983,117,437-458$.

77 (a) W. Wernsdorfer, N. E. Chakov and G. Christou, Phys. Rev. B: Condens. Matter Mater. Phys., 2004, 70, 132413; (b) W. Wernsdorfer, Supercond. Sci. Technol., 2009, 22, 064013.

78 X. Guo, G. Zhu, Z. Li, F. Sun, Z. Yang and S. Qiu, Chem. Commun., 2006, 3172-3174.

79 Q. Zhou, F. Yang, B. Xin, G. Zeng, X. Zhou, K. Liu, D. Ma, G. Li, Z. Shi and S. Feng, Chem. Commun., 2013, 49, 82448246.

80 X. Zhang, V. Vieru, X. Feng, J.-L. Liu, Z. Zhang, B. Na, W. Shi, B.-W. Wag, A. K. Powell, L. F. Chibotaru, S. Gao, P. Cheng and J. R. Long, Angew. Chem., Int. Ed., 2015, 54, 9861-9865.

81 J.-Y. Ge, L. Cui, J. Li, F. Yu, Y. Song, Y.-Q. Zhang, J.-L. Zuo and M. Kurmoo, Inorg. Chem., 2017, 56, 336-343.

82 (a) L. F. Chibotaru, L. Ungur and A. Soncini, Angew. Chem., Int. Ed., 2008, 47, 4126-4129; (b) L. Ungur, W. Van den Heuvel and L. F. Chibotaru, New J. Chem., 2009, 33, 1224-1230.

83 (a) T. Yamada, S. Kobatake, K. Muto and M. Irie, J. Am. Chem. Soc., 2000, 122, 1589-1592; (b) T. Yamada, S. Kobatake and M. Irie, Bull. Chem. Soc. Jpn., 2000, 73, 2179-2184; (c) S. Kobatake, K. Uchida, E. Tsuchida and M. Irie, Chem. Commun., 2002, 2804-2805; (d) S. Kobatake and M. Irie, Bull. Chem. Soc. Jpn., 2004, 77, 195-210; (e) M. Morimoto and M. Irie, Chem. Commun., 2005, 38953905; (f) S. Kobatake, S. Takami, H. Muto, T. Ishikawa and M. Irie, Nature, 2007, 446, 778-781; $(g)$ M. Irie, Bull. Chem. Soc. Jpn., 2008, 8, 917-926.

84 (a) M. Irie, Chem. Rev., 2000, 100, 1685-1716; (b) H. Tian and S. Yang, Chem. Soc. Rev., 2004, 33, 85-97.

85 M. Morimoto, H. Miyasaka, M. Yamashita and M. Irie, J. Am. Chem. Soc., 2009, 131, 9823-9835.

86 T. Shiga, H. Miyasaka, M. Yamashita, M. Morimoto and M. Irie, Dalton Trans., 2011, 40, 2275-2282.

87 (a) J.-P. Costes, F. Dahan, A. Dupuis and J.-P. Laurent, Inorg. Chem., 1996, 35, 2400-2402; (b) J.-P. Costes, F. Dahan, A. Dupuis and J.-P. Laurent, Inorg. Chem., 1997, 36, 3429-3433; (c) J.-P. Costes, F. Dahan and A. Dupuis, Inorg. Chem., 2000, 39, 165-168; (d) T. Kajiwara, M. Nakano, S. Takaishi and M. Yamashita, Inorg. Chem., 2008, 47, 8604-8606; (e) M. Sakamoto, K. Manseki and 
H. O. kawa, Coord. Chem. Rev., 2001, 219-221, 379-414; (f) R. E. P. Winppeny, Chem. Soc. Rev., 1998, 27, 447-452; (g) S. Osa, T. Kido, N. Matsumoto, N. Re, A. Pochaba and J. Mrozinski, J. Am. Chem. Soc., 2004, 126, 420-421; (h) F. He, M.-L. Tong and X.-M. Chen, Inorg. Chem., 2005, 44, 8285-8292; (i) J.-P. Costes, F. Dahan and W. Wernsdorfer, Inorg. Chem., 2006, 45, 5-7; (j) J.-P. Costes, M. Auchel, F. Dahan, V. Peyrou, S. Shova and W. Wernsdorfer, Inorg. Chem., 2006, 45, 1924-1934; (k) R. Gheorghe, M. Andruh, J.-P. Costes and B. Donnadieu, Chem. Commun., 2003, 2778-2779; (l) R. Gheorghe, P. Cucos, M. Andruh, J.-P. Costes, B. Donnadieu and S. Shova, Chem. - Eur. J., 2006, 12, 187203; $(\mathrm{m})$ J. Long, L.-M. Chamoreau and V. Marvaud, Dalton Trans., 2010, 39, 2188-2190; (n) M. Andruh, Chem. Commun., 2007, 2565-2567; (o) M. Andruh, J.-P. Costes, C. Diaz and S. Gao, Inorg. Chem., 2009, 48, 3342-3359.

88 M. Morimoto and M. Irie, Chem. - Eur. J., 2006, 12, 42754282.

89 D. Pinkowicz, M. Ren, L.-M. Zheng, S. Sato, M. Hasegawa, M. Morimoto, M. Irie, B. K. Breedlove, G. Cosquer, K. Katoh and M. Yamashita, Chem. - Eur. J., 2014, 20, 12502-11513.

90 G. Cosquer, M. Morimoto, M. Irie, A. Fetoh, B. K. Breedlove and M. Yamashita, Dalton Trans., 2015, 44, 5996-6002.

91 G. Cosquer, M. Kamila, Z.-Y. Li, B. K. Breedlove and M. Yamashita, Inorganics, 2018, 6, 9-19.

92 (a) D.-P. Li, T.-W. Wang, C.-H. Li, D.-S. Liu, Y.-S. Li and X.-Z. You, Chem. Commun., 2010, 46, 2929-2931; (b) L. Norel, K. Bernot, M. Feng, T. Roisnel, A. Caneschi, R. Sessoli and S. Rigaut, Chem. Commun., 2012, 48, 39483950; (c) G.-J. Chen, Y.-N. Guo, J.-L. Tian, J. Tang, W. Gu, X. Liu, S.-P. Yan, P. Cheng and D.-Z. Liao, Chem. - Eur. J., 2012, 18, 2484-2487; (d) T. T. Da Cunha, J. Jung, M.-E. Boulon, G. Campo, F. Pointillart, C. Pereira, B. Le Guennic, O. Cador, K. Bernot, F. Pineider, S. Golhen and L. Ouahab, J. Am. Chem. Soc., 2013, 135, 16332-16335; (e) F. Pointillart, J. Jung, R. Berraud-Pache, B. Le Guennic, V. Dorcet, S. Golhen, O. Cador, O. Maury, Y. Guyot, S. Decurtins, S.-X. Liu and L. Ouahab, Inorg. Chem., 2015, 54, 5384-5397; $(f)$ Y. Bi, Y.-N. Guo, L. Zhao, Y. Guo, S.-Y. Lin, S.-D. Jiang, J. Tang, B.-W. Wang and S. Gao, Chem. - Eur. J., 2011, 17, 12476-12481; (g) G. Cosquer, F. Pointillart, S. Golhen, O. Cador and L. Ouahab, Chem. Eur. J., 2013, 19, 7895-7903; (h) M. Perfetti, M. Gysler, Y. Rechkemmer-Patalen, P. Zhang, H. Tastan, F. Fischer, J. Netz, W. Frey, L. W. Zimmermann, T. Schleid, M. Hakl, M. Orlita, L. Ungur, L. Chibotaru, T. Brock-Nannestad, S. Piligkos and J. van Slageren, Chem. Sci., 2019, 10, 21012110; ( $i$ ) B. Lefeuvre, O. Galangau, J. Flores Gonzalez, V. Montigaud, V. Dorcet, L. Ouahab, B. Le Guennic, O. Cador and F. Pointillart, Front. Chem., 2018, 6, 552563; $(j)$ J. Flores Gonzalez, V. Montigaud, N. Saleh, O. Cador, J. Crassous, B. Le Guennic and F. Pointillart, Magnetochemistry, 2018, 4, 39-49.
93 (a) Y.-C. Ou, W.-T. Liu, J.-Y. Li, G.-G. Zhang, J. Wang and M.-L. Tong, Chem. Commun., 2011, 47, 9384-9386; (b) M. Nagarathinam and J. J. Vittal, Chem. Commun., 2008, 438-440; (c) I.-H. Park, R. Medishetty, J.-Y. Kim, S. S. Lee and J. J. Vittal, Angew. Chem., Int. Ed., 2014, 53, 5591-5595; (d) K. M. Hutchins, T. P. Rupasinghe, L. R. Ditzler, D. C. Swenson, J. R. G. Sander, J. Baltrusaitis, A. V. Tivanski and L. R. MacGillivray, J. Am. Chem. Soc., 2014, 136, 6778-6781; (e) X.-Y. Wang, Z.-M. Wang and S. Gao, Chem. Commun., 2007, 11271129; $(f)$ H. Sato, R. Matsuda, M. H. Mira and S. Kitagawa, Chem. Commun., 2012, 48, 7919-7921.

94 L.-F. Wang, J.-Z. Qiu, J.-L. Liu, Y.-C. Chen, J.-H. Jia, J. Jover, E. Ruiz and M.-L. Tong, Chem. Commun., 2015, 51, 15358-15361.

95 J. Ruiz, A. J. Mota, S. Rodriguez-Dieguez, S. Titos, J. M. Herrera, E. Ruiz, E. Cremades, J.-P. Costes and E. Colacio, Chem. Commun., 2012, 48, 7916-7918.

96 (a) R. J. Guglielmetti and J. C. Crano, in Topics in Applied Chemistry, Vol. 1, Main photochromic families, ed. A. R. Katritzky, Kluwer Academic Publisher, 2002; (b) G. Berkovic, V. Krongauz and V. Weiss, Chem. Rev., 2000, 100, 1741-1753; (c) M. M. Russew and S. Hecht, Adv. Mater., 2010, 22, 3348-3360; (d) S. V. Paramonov, V. Lokshin and O. A. Fedorova, J. Photochem. Photobiol., C, 2011, 12, 209-236; (e) J. J. Zhang, Q. Zou and H. Tian, Adv. Mater., 2013, 25, 378-399; (f) M. Natali and S. Giordani, Chem. Soc. Rev., 2012, 41, 4010-4029.

97 V. I. Minkin, Chem. Rev., 2004, 104, 2751-2776.

98 (a) Z. Y. Tian and A. D. Q. Li, Acc. Chem. Res., 2013, 46, 269-279; (b) R. Klajn, Chem. Soc. Rev., 2014, 43, 148-184; (c) Q. Qi, C. Li, X. Liu, S. Jiang, Z. Xu, R. Lee, M. Zhu, B. Xu and W. Tian, J. Am. Chem. Soc., 2017, 139, 1603616039.

99 P. Nuernberger, S. Ruetzel and T. Brixner, Angew. Chem., Int. Ed., 2015, 54, 11368-11386.

100 P. Selvanathan, V. Dorcet, T. Roisnel, K. Bernot, G. Huang, B. Le Guennic, L. Norel and S. Rigaut, Dalton Trans., 2018, 47, 4139-4148.

101 P. Selvanathan, G. Huang, T. Guizouarn, T. Roisnel, G. Fernandez-Garcia, F. Totti, B. Le Guennic, G. Calvez, K. Bernot, L. Norel and S. Rigaut, Chem. - Eur. J., 2016, 22, 15222-15226.

102 H. Tian, J.-B. Su, S.-S. Bao, M. Kurmoo, X.-D. Huang, Y.-Q. Zhang and L.-M. Zheng, Chem. Sci., 2018, 9, 64246433.

103 A. J. Brown, D. Pinkowicz, M. R. Saber and K. R. Dunbar, Angew. Chem., Int. Ed., 2015, 54, 5864-5868.

104 (a) I. J. Hewitt, J. Tang, N. T. Madhu, C. E. Anson, Y. Lan, J. Luzon, M. Etienne, R. Sessoli and A. K. Powell, Angew. Chem., Int. Ed., 2010, 49, 6352-6356; (b) J. J. Le Roy, M. Jeletic, S. I. Gorelsky, I. Korobkov, L. Ungur, L. F. Chibotaru and M. Murugesu, J. Am. Chem. Soc., 2013, 135, 3502-3510; (c) K. L. M. Harriman, J. L. Brosmer, L. Ungur, P. L. Diaconescu and M. Murugesu, J. Am. Chem. Soc., 2017, 39, 1420-1423; (d) B. S. Dolinar, 
D. I. Alexandropoulos, K. R. Vignesh, T. James and K. R. Dunbar, J. Am. Chem. Soc., 2018, 140, 908-911.

105 Z. Liang, M. Damjanovic, M. Kamila, G. Cosquer, B. K. Breedlove, M. Enders and M. Yamashita, Inorg. Chem., 2017, 56, 6512-6521.
106 D. Tanaka, T. Inose, H. Tanaha, S. Lee, N. Ishikawa and T. Ogawa, Chem. Commun., 2012, 48, 7796-7798.

107 G. A. Spyroulia, C. P. Raptopoulou, D. D. Montauzon, A. Mari, R. Poilblanc, A. Terzis and A. G. Coutsolelos, Inorg. Chem., 1999, 38, 1683-1699. 